\title{
Wave energy resource variation off the west coast of Ireland and its impact on realistic wave energy converters' power absorption
}

\author{
Markel Penalba $^{\mathrm{a}, *}$, Alain Ulazia ${ }^{\mathrm{b}}$, Gabriel Ibarra-Berastegui ${ }^{\mathrm{e}, \mathrm{c}}$, John Ringwood ${ }^{\mathrm{a}}$, Jon Sáenz ${ }^{\mathrm{d}, \mathrm{e}}$ \\ ${ }^{\text {a }}$ Centre for Ocean Energy Research, Maynooth University, Maynooth, Co. Kildare, Ireland \\ ${ }^{\mathrm{b}}$ Department of NE and Fluid Mechanics, University of the Basque Country (UPV/EHU), Otaola 29, 20600 Eibar, Spain \\ ${ }^{\mathrm{c}}$ Department of NE and Fluid Mechanics, University of the Basque Country (UPV/EHU), Alda. Urkijo, 48013 Bilbao, Spain \\ ${ }^{\mathrm{d}}$ Department of Applied Physics II, University of the Basque Country (UPV/EHU), B. Sarriena s/n, 48940 Leioa, Spain \\ e Joint Research Unit (UPV/EHU-IEO) Plentziako Itsas Estazioa (PIE), University of Basque Country (UPV/EHU), Areatza Hiribidea 47, 48620 Plentzia, Spain
}

\section{H I G H L I G H T S}

- Historical wave trends are studied via ECMWF's reanalyses over the 20th century.

- ERA20 is calibrated via quantile-matching and validated against buoy measurements.

- The wave energy resource increases over $40 \%$ off the west coast of Ireland.

- A 30\% surplus of AMPP is observed for different WECs due to resource variations.

- Extreme events occurrence doubled, doubling the time WECs spend in survival mode.

\section{A R T I C L E I N F O}

\section{Keywords:}

Wave energy trends

ERA-Interim

ERA-20C

Wave energy converters

Power absorption

Extreme events

\begin{abstract}
A B S T R A C T
Wave energy converters are specifically designed to extract the maximum energy from a given location. To that end, wave data statistics based on past measures at the given location are commonly used, neglecting any possible future wave trend. This paper studies the variations of the wave energy resource off the west coast of Ireland over the 20th century via the atmospheric reanalyses created by the European Centre for Medium-Range Weather Forecasts. In particular, the European Re-Analysis ERA20 is calibrated via quantile-matching against the new European Re-Analysis ERA-Interim for the period 1979-2010. In addition, the calibrated ERA20 reanalysis is validated against buoy measurements in the area of interest. Results show a significant increase of the wave energy resource along the last century (an increase of over 40\%), for which the largest increase is observed within the last 20 years (an increase of 18\% between 1980 and 2000). The paper shows that these variations considerably affect the power absorption of realistic devices, showing a power surplus of up to $15 \%$ within the lifespan of a wave energy converter. Finally, an increase of extreme events over the last century is also observed, highlighting its impact on power production due to the need of wave energy converters to switch into survival mode during extreme events.
\end{abstract}

\section{Introduction}

In the way to reduce greenhouse emissions and mitigate the effects of climate change, renewable energy systems play a crucial role. Renewable energies already cover almost $20 \%$ of the total final energy consumption in the world, where hydropower, biomass, solar and wind energy are currently the main contributors to the national electricity grids all over the world [1]. However, other renewable energy sources, such as wave energy, have the potential to also contribute to the energy mix. The worldwide potential of wave energy is estimated to be around $32,000 \mathrm{TWh} /$ year [2], which suggests that wave energy can be a good candidate to increase the weight of renewable energies in the energy mix.

Despite the enormous power stored in ocean waves, the harsh environment in which wave energy converters (WECs) need to operate makes the energy production from ocean waves complex and costly [3]. In addition, several different WEC concepts have been suggested by researchers and developers [4], but none of the concepts has

\footnotetext{
* Corresponding author.

E-mail addresses: markel.penalbaretes.2015@mumail.ie (M. Penalba), alain.ulazia@ehu.eus (A. Ulazia), gabriel.ibarra@ehu.eus (G. Ibarra-Berastegui), john.ringwood@mu.ie (J. Ringwood), jon.saenz@ehu.eus (J. Sáenz).
} 
demonstrated commercial viability yet.

Once commercial viability is achieved for any WEC concept, an accurate characterisation of the resource at the location where the WEC, or WEC farm, is to be deployed will be vital. The wave energy resource of a specific location is often presented in scatter diagrams that are generated using only past measurements [5]. These scatter diagrams are characterised by two main variables: peak period $\left(T_{p}\right)$ and significant wave height $\left(H_{s}\right)$. However, only considering past data neglects any possible variation of the resource in the period where the WEC is supposed to operate, meaning that WECs designed using these scatter diagrams are designed for the past resource, while deployed in the future resource.

Therefore, wave resource variations must be considered to accurately design WECs. Following the recommendations by the World Meteorological Organization [6,7], reliable estimations of climate variables require at least 30 years of data. This data may be obtained by means of different techniques, such as buoy measurements [8], observations from ships $[9,10]$, satellite altimeter $[11,12]$ or models and reanalysis datasets [13-20]. The latter method, i.e. reanalysis datasets, is used in the present study, using atmospheric reanalyses of the European Centre for Medium-Range Weather Forecasts (ECMWF). Among the different options, the European Re-Analysis ERA20C is used, calibrated against the ERA-Interim reanalysis via the empirical quantile-matching technique.

\subsection{Literature review}

Reanalysis datasets are employed for different applications in the literature. For example, a global wave energy resource study is carried out in $[18,20]$ using a 40 -year reanalysis ERA40, which is the previous version of the reanalysis based on the Wave Modeling Project (WAM) ERA-Interim-WAM. Both $[18,20]$, are large-scale studies focused on worldwide climate patterns, where [18] calculates wave trends by means of linear regression, while [20] uses a method based on swell index and the propagation characteristics of swell energy. Similarly, Ref. [19] presents a global study of the wave energy resource.

Similar methods are also used to estimate wave height trends of the North Atlantic Ocean in [17], where the ERA20C reanalysis is used. In this particular case, wave height trends are studied in relation to wind speed variations. However, Ref. [17] uses results obtained from ERA20C without calibration, since the aim of the study is analysing the effect of climate change in wave height trends. Apart from reanalysis datasets, other techniques have widely been used to document wave height variations all over the world, where Ireland is a particularly well reported area due to the very energetic waves and high variability. For example, Ref. [12] studies wave height variations off the west coast of Ireland between 1985 and 2008 using satellite data and shows an annual increase of approximately $0.25 \%$, which indicates a trend of more than $5 \mathrm{~cm} /$ decade based on an average $3 \mathrm{~m}$-wave. In situ observations near Ireland have also been used to document wave height variations. Bouws et al. [21] uses historical hand-drawn charts of the south of England and shows a positive trend in wave height of $24 \mathrm{~cm} /$ decade over the period 1960-1985. In addition, Refs. [9,10,22] use centennial time series of visually observed waves from ship routes to report wave height trends in the North Atlantic Ocean, demonstrating positive trends for $H_{s}$ of up to $14 \mathrm{~cm} /$ decade. Based on these visual observations, Gulev created a European map of wave height trends, indicating a trend of approximately $5 \mathrm{~cm} /$ decade off the west coast of Ireland. This wave height trend is consistent with the results presented in [12] and in the present paper.

The vast majority of wave trend studies, as described in the above paragraph, focus on wave height trends, while wave period trends are often neglected. Presumably, the main reason to neglect wave period trends is that wave period variations are of little interest for other research areas or industries than wave energy, which is still an immature industry. Some very recent research works study wave period variations by means of statistical models similar to those used in the present paper: wave period trends in the Bay of Bengal are analysed in [23] combining satellite altimeter data with ERA-Interim and ERA-20 reanalyses and the evolution of peak periods and wave heights is studied all over the world in [24]. However, wave period trends are analysed for coastal impact assessment in [23,24], where wave climate variations are rather projected towards the future (1979-2100), instead of studying historical records of the last century, as in the present paper. Although [24] is a global study, more localised areas, such as Southern Australia and Western South America, are also selected for finer studies. Unfortunately, these more localised areas are far from the area of study evaluated in the present paper, so results cannot be compared as with wave height trends.

Other potential methods for the study of wave period and height trends include satellite and remote sensing data. Apart from altimetric data directly related to the significant wave height, satellites like TOPEX, ENVISAT or Sentinel also record a second parameter, the backscatter coefficient $\left(\sigma_{0}\right)$ of the electromagnetic signal, which, in combination with the wave height, allows for the estimation of the mean wave period [25-28]. However, wave period observations by means of satellite and remote sensor have been considered unreliable until 2005 [25]. In addition, the vast majority of the studies in the literature analyse the wave power density from a pure climatological perspective, only analysing the pure resource. Therefore, no special attention has been paid to period trends.

Nonetheless, wave period variations are crucial to accurately evaluate the impact of wave energy resource variations on WEC's power absorption. The only study that includes wave height and period variations, to the authors' knowledge, is a preliminary study carried out in the Bay of Biscay by the same authors [29], where significant increment of the resource and absorbed power are observed over the 20th century. However, the impact of wave resource variations on WEC's in [29] is analysed using a generic WEC with a spherical geometry and a excessively simplified WEC model.

Other studies that analyse the wave energy resource at different points all over the world using similar reanalyses or mesoscale models, consider wave heights, wave periods and wave directionality [30,31]. However, these studies are based on hindcast data that covers at most two times the lifespan of a WEC (approximately 20 years). In addition, the aim of these studies is the assessment of the resource at specific locations with high spatio-temporal resolution, which is performed via the wave energy transformation model SWAN using calibrated sourceterm parameters, and, as a consequence, only seasonal or inter-annual variabilities are analysed.

The present paper presents a novel methodology to analyse the historical evolution of the wave energy resource and evaluates resource variations off the west coast of Ireland over the whole 20th century for the first time. The insight provided by the analysis of the historical evolution of the wave resource along a whole century is significantly more valuable to understand historical wave trends and, eventually, the future resource and its impact on the power production of WECs. Therefore, this paper focuses on wave period, wave height and wave energy flux (WEF) variations over the 20th century, similarly to [29]. However, the present paper includes substantial improvements that provide more consistent results. Firstly, the methodology to assess wave energy resource variations is validated in a completely different location: The Bay of Biscay studied in [29] is a rather closed area where the wave resource is mild (about $20 \mathrm{~kW} / \mathrm{m}$ ), while the west coast of Ireland analysed in the present paper is open to the Atlantic Ocean and the wave resource is considerably higher $(60 \mathrm{~kW} / \mathrm{m})$. Second, the impact of wave energy resource variations on WECs' power absorption is studied using two fundamentally different WECs based on full-scale real prototypes. Third, a more accurate hydrodynamic model that considers time-domain dynamics, multiple degrees of freedom (DoFs) and constraints is employed. Finally, variations of extreme events and the consequences of turning the WEC into the survivability mode during 
extreme events are evaluated.

The remainder of the paper is as follows: Sections 2 and 3 present the data and the methodology to study the wave trends, respectively, Section 4 describes the realistic WECs and the hydrodynamic model employed to evaluate the power absorption of the WECs, Section 5 shows the results related to resource variations and the power absorbed by realistic WECs, Section 6 discusses the results and suggests future lines of research, and 7 presents the conclusions.

\section{Wave data}

Wave data from different sources is analysed in this paper, which is adequately combined to obtain validated and reliable data for the evaluation of wave resource variations and their impact on WEC's performance. On the one hand, two different ECMWF's reanalyses, i.e. ERA-20C (henceforth referred to as ERA20) and ERA-Interim (referred to as ERAI in the following), are used:

- ERA20 is the first reanalysis of the 20th century that includes data from 1900 to 2010 [32]. The ERA20 reanalysis assimilates historical observations from the International Comprehensive Ocean-Atmosphere Data Set on surface pressure and winds [33] by means of the 24-h 4D-Var analysis method. The spatial resolution is approximately $125 \mathrm{~km}$ and the temporal resolution is 3-h. It should be noted that the quality of the data obtained from ERA2O is, in general, better in the Northern Hemisphere than in the Southern Hemisphere [32]. However, the ERA20 reanalysis has been used in both hemispheres, e.g. for the study of long-term coastal evolution $[34,23]$ and the global study of the relation between historical extreme waves and climate change [35].

- ERAI is a global reanalysis updated every month and contains data since 1979 [36]. The data assimilation method in this case is the 12h 4D-Var analysis method and the wave model is based on the WAM approach [37,38]. The spatial resolution is approximately $75 \mathrm{~km}$ (ERA20 is almost two times coarser) and time outputs are achieved every $6 \mathrm{~h}$.

On the other hand, data from four wave-measuring buoys deployed in the area of interest are used for the validation. Fig. 1 presents the area of interest and the four buoys chosen from the resources offered by the Irish Marine Institute [39].

Table 1 presents the geographical position of the four buoys, the distance between the buoys and the nearest gridpoint of the ERA20

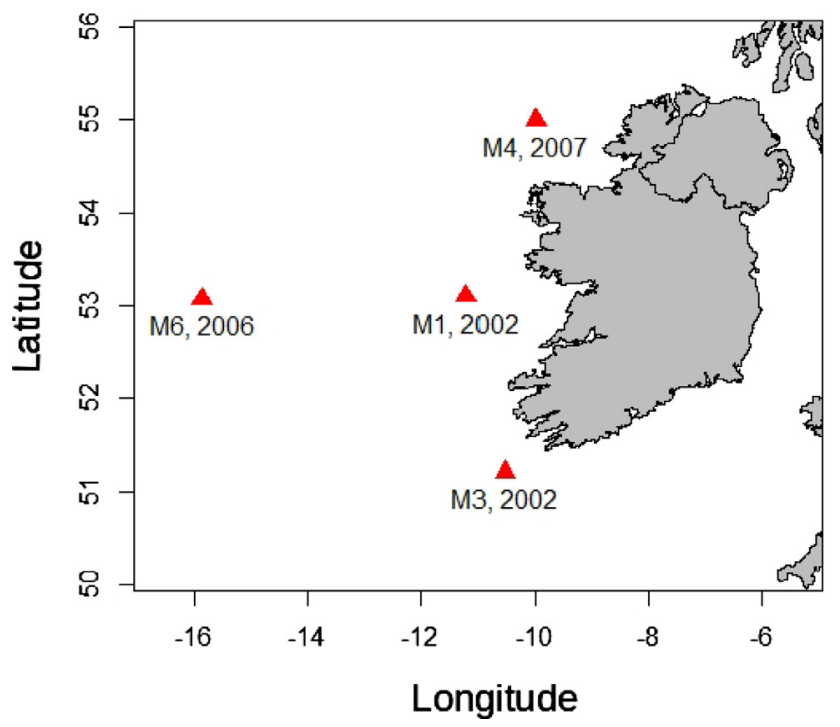

Fig. 1. The study area and the four buoys.
Table 1

Buoys on Ireland.

\begin{tabular}{lccc}
\hline Buoy & Position (lon, lat) & Nearest gridpoint & Validation Period \\
\hline M1 & $(-11.2,53.1)$ & $27 \mathrm{~km}$ & $2003-2010$ \\
M3 & $(-10.5,51.2)$ & $71 \mathrm{~km}$ & $2002-2010$ \\
M4 & $(-10.0,55.0)$ & $26 \mathrm{~km}$ & $2007-2010$ \\
M6 & $(-15.9,53.1)$ & $23 \mathrm{~km}$ & $2006-2010$ \\
\hline
\end{tabular}

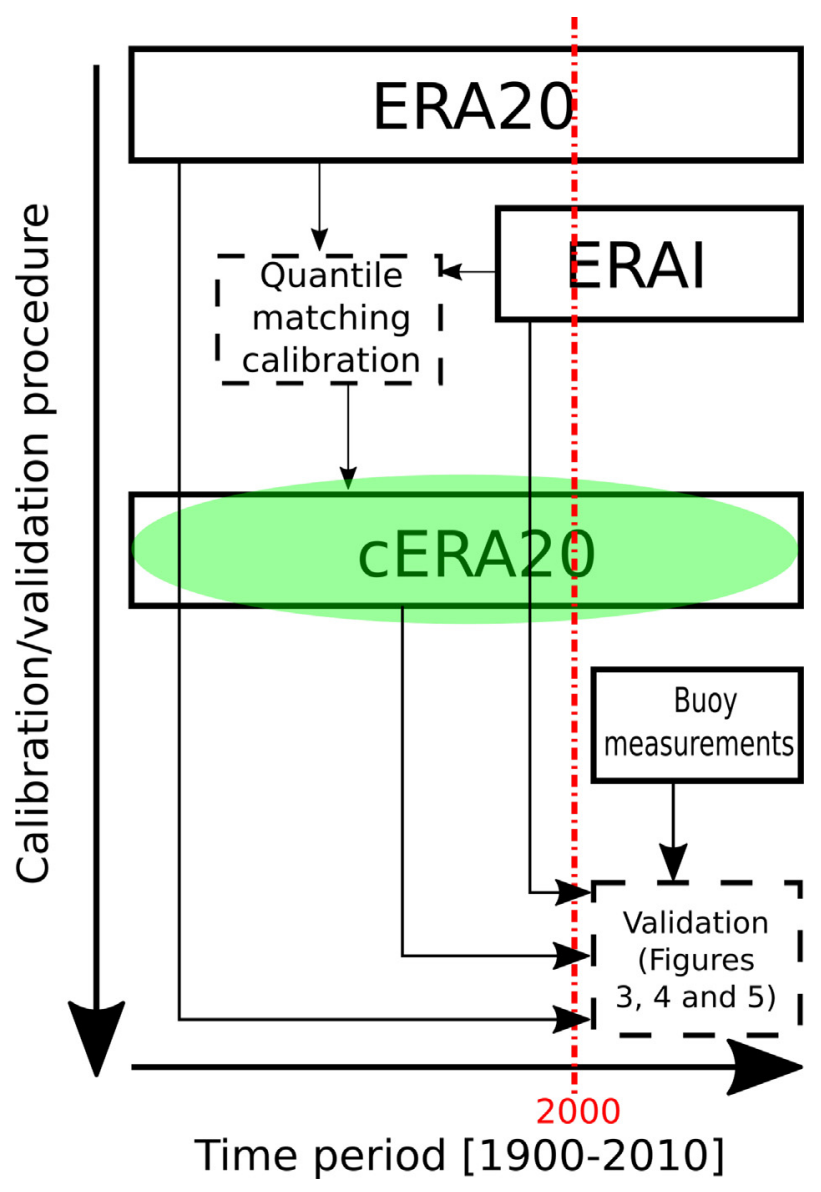

Fig. 2. Flow-diagram of the calibration/evaluation method.

reanalysis, and the period during which the validation between the reanalysis and the buoy measurements is performed.

For the validation of the reanalysis against the buoy measurements, 6-hourly data is used. In contrast, for the posterior calibration and wave trend evaluation, monthly mean values obtained from daily mean values, are employed.

\section{Reanalysis calibration and validation}

The whole procedure, including the calibration and the validation, is graphically illustrated in Fig. 2. The horizontal axis shows the time period between 1900 and 2010, illustrating the time-scale considered by each reanalysis and wave-measuring buoys, and the vertical axis shows the order in which the calibration/validation procedure is carried out.

Hence, wave energy resource parameters are transformed from the original ERA20 data to their calibrated counterparts by establishing the same quantile value in the cumulative distribution function (CDF) curves of ERA20 and ERAI. Once the calibrated reanalysis, referred to as CERA20, is obtained, results from CERA20 are validated against buoy measurements.

The calibration of the ERA20 reanalysis is carried out against the 
ERAI reanalysis using the WEF as the basis, which can be calculated with $H_{s}$ and mean period $\left(T_{m}\right)$ [40] as follows,

$W E F=0.49 H_{s}^{2} T_{m}$,

In turn, $H_{s}$ and $T_{m}$ are obtained from the wave spectral moments $m_{0}$ and $m_{-1}$,

$H_{s}=4 \sqrt{m_{0}}$,

$T_{m}=m_{-1} / m_{0}$,

where spectral moments are given by,

$m_{n}=\int_{0}^{\infty} \omega^{n} S(\omega) d \omega, n=-1,0,1,2 \ldots$,

$\omega$ is the wave frequency and $S(\omega)$ the wave spectrum.

However, the wave-measuring buoys used in this study provide the information related to the wave period via the average zero-crossing period $\left(T_{z}=\sqrt{m_{0} / m_{2}}\right)$. Therefore, Eq. (1) needs to be adapted to include $T_{z}$. To that end, the wave period ratio $\left(W P R=T_{m} / T_{z}\right)$ is usually defined to calculate the WEF [40] as follows,

$W E F=W P R \cdot 0.49 H_{s}^{2} T_{z} ;$

Absorbed power from WECs is calculated using the WEF matrices or scatter diagrams, which is commonly characterised by $T_{p}$, rather than $T_{m}$ or $T_{z}$ [41]. However, ERA20 and ERAI already provide $T_{p}$ as a parameter of the wave field and, as a consequence, the correction of the WEF based on the WPR is only used for the validation of the reanalysis against in situ buoy observations.

The calibration technique utilised in this paper is a relatively simple and fundamentally statistical procedure based on distribution mapping. The objective of this technique is matching the values with the same quantile from two empirical probability distributions: the distribution of the pre-calibrated dataset (ERA20) and the distribution of the dataset used as the basis for the calibration (ERAI). This technique has previously been used for different applications and is also known as 'probability mapping' [42], 'quantile-quantile mapping' [43,44], 'statistical downscaling' [45] or 'histogram equalization' [46]. The same bias correction procedure has already been used for the calibration of the ERA20 against ERAI in [47], or more recently in [48]. In addition, the quantile-matching technique is also implemented for the study of extreme climate events in [49], which is a relevant application for the present study, since extreme events are also analysed here.

Other calibration and bias correction techniques can be found in the literature, comparing reanalysis data against observations or reanalysis data at different spatial and temporal scales for different applications, such as variations of precipitations or temperatures [50-53].

WEF results obtained from the different reanalyses, excluding cERA20, and the observations in the four points described in Table 1 are compared in Table 2. The second column shows the WPR values at the four locations, which are consistent with previous studies at different locations off the west coast of Ireland, such as Loop Head and the Atlantic Marine Energy Test Site (AMETS) [40]. The third column illustrates the observation interval (Obs. interval) that shows the WEF values from observations without and with the WPR adaptation. The last two columns present the WEF values for the reanalyses ERAI and ERA20. One can observe that WEF values from the ERAI reanalysis lie always within the observation interval, while values from ERA20

Table 2

Mean WEF in the four bouys for the observation and the two reanalysis.

\begin{tabular}{lcccc}
\hline Buoy & WPR & Obs. interval $[\mathrm{kW} / \mathrm{m}]$ & ERAI $[\mathrm{kW} / \mathrm{m}]$ & ERA20 $[\mathrm{kW} / \mathrm{m}]$ \\
\hline M1 & 1.25 & $48.3-60.3$ & 58.9 & 42.1 \\
M3 & 1.29 & $41.6-54.1$ & 47.4 & 36.8 \\
M4 & 1.30 & $48.3-62.7$ & 55.2 & 48.3 \\
M6 & 1.27 & $64.3-81.6$ & 69.6 & 52.4 \\
\hline
\end{tabular}

Table 3

WEF 90-95\% percentiles at the four buoys for the observation and the two reanalysis.

\begin{tabular}{lccc}
\hline Buoy & Obs. interval $[\mathrm{kW} / \mathrm{m}]$ & ERAI $[\mathrm{kW} / \mathrm{m}]$ & ERA20 $[\mathrm{kW} / \mathrm{m}]$ \\
\hline M1 & $147.9-218.3$ & $145.9-217.6$ & $104.1-158.3$ \\
M3 & $122.2-191.6$ & $115.7-172.8$ & $91.1-141.0$ \\
M4 & $132.2-205.6$ & $134.6-198.8$ & $114.9-177.4$ \\
M6 & $191.6-277.3$ & $163.9-241.8$ & $123.8-187.5$ \\
\hline
\end{tabular}

always lie out of that interval. Table 2 also shows that ERA20 always underestimates the WEF, which reinforces the value of ERAI as the basis for the calibration.

Similarly to Tables 2 and 3 illustrates the $90-95 \%$ quantiles for the observations, and ERAI and ERA20 reanalyses. Table 3 shows again that ERA20 underestimates the WEF, while ERAI shows good agreement with the observations, particularly at high-energetic sea-states. The good characterisation of high-energetic sea-states is essential for a good wave trend estimation.

Apart from the 90-95\% quartiles presented in Table 3, ERAI and ERA20 capture properly the 25th, 50th and 75th quartiles, as shown in Fig. 3. ERAI and, especially ERA20, slightly fail in reproducing the WEF at M6, which is the buoy that is located in open ocean and shows the highest quartile values. An important point to highlight in Fig. 3 is that cERA20 always provides a better representation of the WEF compared to ERA20, demonstrating the benefits of the calibration.

The benefits of the calibration, compared to the non-calibrated reanalyses and buoy measurements, can also be evaluated by means of three statistical metrics: the root mean square error (RMSE), the Pearson correlation, and the standard deviation ratio (SDratio) between the model and the observations. Taylor diagrams allow for the representation of these three metrics in a single graph, where.

- RMSE is given by the arc with the centre in the observation point,

- Pearson correlation coefficient is represented by the exterior arc, and

- SDratio is illustrated by the arc with the centre at the origin.

Fig. 4 illustrates the Taylor diagrams for each buoy, where the CERA20 reanalysis shows an important improvement in terms of SDratio and RMSE in M1, M3 and M4 compared to the ERA20 reanalysis. The improvement in RMSE is also significant, bringing the calibrated data's RMSE from approximately $40 \mathrm{~kW} / \mathrm{m}$ to $30 \mathrm{~kW} / \mathrm{m}$ in $\mathrm{M} 1$, from $40 \mathrm{~kW} / \mathrm{m}$ to $35 \mathrm{~kW} / \mathrm{m}$ in M3, and from $60 \mathrm{~kW} / \mathrm{m}$ to $50 \mathrm{~kW} / \mathrm{m}$ in M6. In contrast, the correlation of the cERA20 is very similar to that of the ERA20.

In addition, one can observe that the cloud corresponding to cERA20 approaches the arc that defines the SDratio 1 in M1, M3 and M4, suggesting that $c E R A 20$ is able to improve the maximum and minimum values of the time series. With a mean wave power around $60 \mathrm{~kW} / \mathrm{m}$ in the west of Ireland, the RMSE values imply considerable relative errors for the reanalyses used in this paper. However, these errors do not represent an issue for the validation, since the errors represent a high variability of the resource, which is the case in the west coast of Ireland [54,55].

The comparison between buoy measurements and the results from non-calibrated and calibrated reanalyses is also illustrated via scatter diagrams at the four locations described in Table 1 . The scatter diagrams for the four buoys with the occurrence in percentage are shown on the left-hand side column in Fig. 5. The other two columns in Fig. 5 illustrate the results of the ERA20 and cERA20, showing the difference with respect to buoy measurements. The improvement of the calibrated results is demonstrated, with particularly good results in the case of the buoys M1 and M4, as previously illustrated in Fig. 4. Fig. 5 also illustrates the overestimation of the lower-energetic sea-states (sea-states 
M1

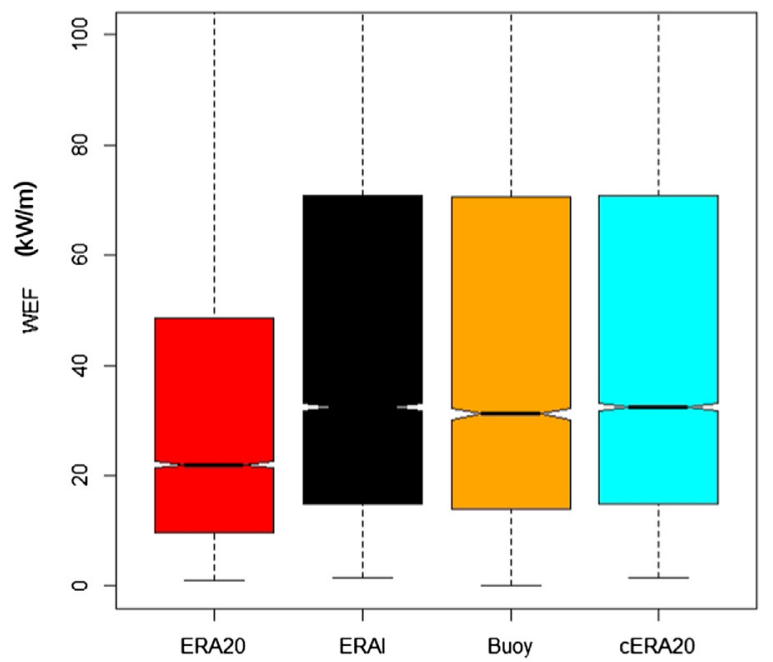

M4

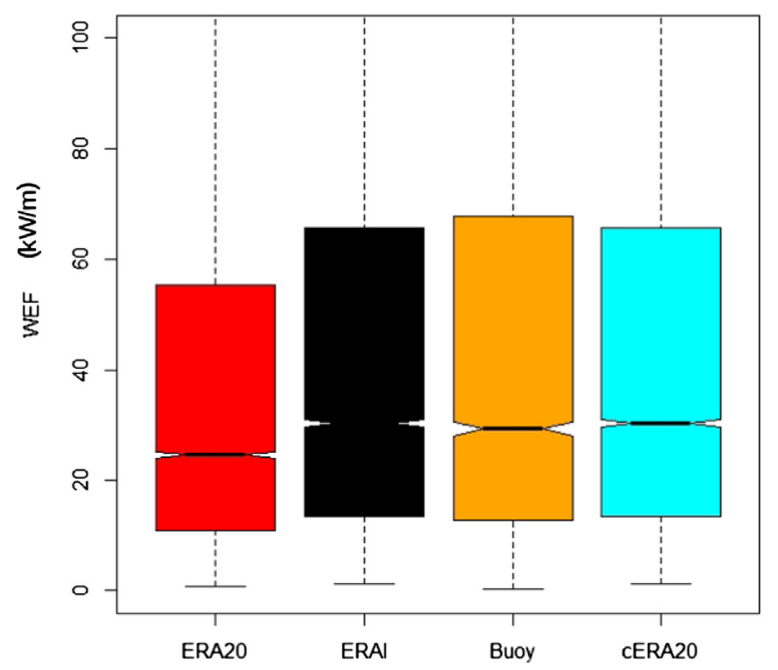

M3

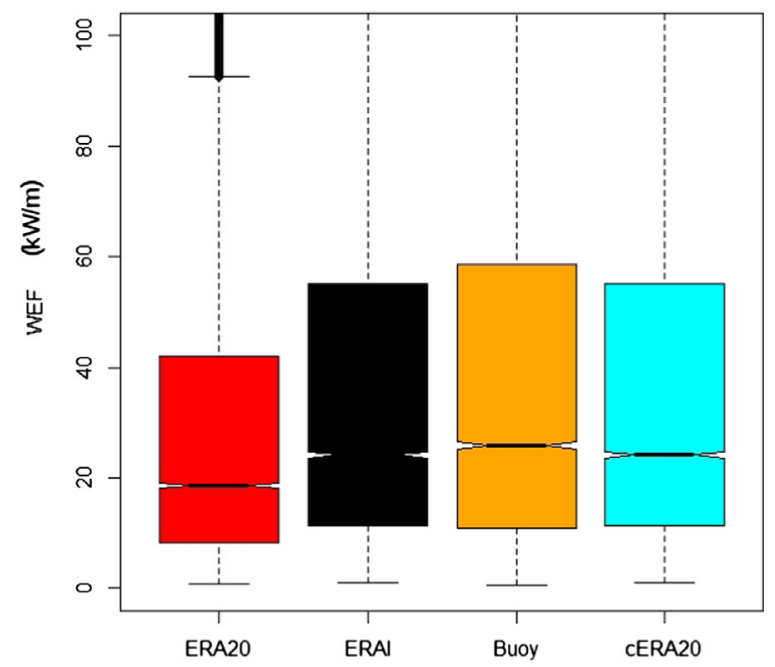

M6

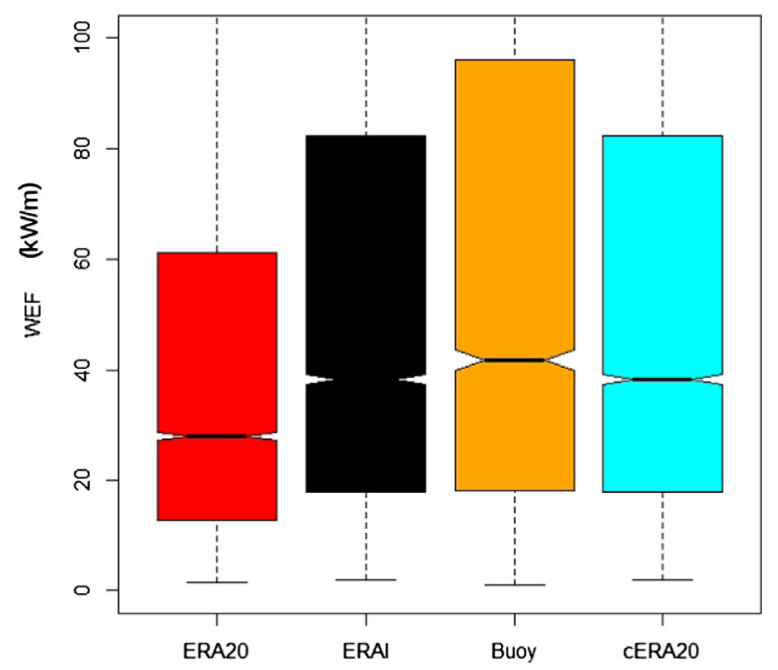

Fig. 3. Quantile Box-plots of ERA20, ERAI, observation and $c E R A 20$ at the four buoys.

with lower wave periods) and the underestimation of higher-energetic sea-states (sea-states with higher wave periods) by the ERA20 reanalysis, as shown in Tables 2 and 3.

Finally, CDF curves are shown in Fig. 6 for ERA20, ERAI, cERA20 and the observations at the buoy M1. The curves for ERAI and cERA20 are identical, so only the curve for cERA20 is shown in Fig. 6 . The curve for CERA2O (and ERAI) shows very good agreement with observations curve, while the curve for the ERA20 reanalysis lies far from the rest of the curves, showing again its inaccuracy.

Among the different results presented in this section for the calibration and validation, the M1 buoy shows the best agreement between cERA2O and the observations. Therefore, the WEF at this location is selected for the evaluation of the power absorption by realistic WECs along the 20th century.

\section{Wave energy conversion}

A wide variety of WECs, based on fundamentally different principles to absorb energy from ocean waves, have been suggested by developers and researchers over the last decades. None of these technologies has demonstrated its superiority over the rest, unlike in the wind industry, and so developers and researchers keep working on different WECs. The different technologies can be classified based on their working principle, as in [4], dividing the different WECs into four main groups: oscillating water column (OWC), point absorbers (PAs), oscillating surge wave converters (OSWCs) and overtopping devices. Other classification methods include the size of the devices and the wave directionality [56] or the location of the devices [57].

Overtopping devices are big fixed or floating structures with an internal water reservoir, and harvest the energy of the waves by capturing the water close to the wave crest when the wave breaks in the structure. The water is stored in the reservoir, extracting the potential energy of the stored water with a hydraulic pump installed underneath the reservoir, as illustrated in Fig. 7(a).

OWC devices are semi-submerged fixed or floating devices with an internal chamber where the air is trapped above the free-surface. The chamber is connected to the atmosphere through an orifice, where the air-turbine is set, as shown in Fig. 7(d). The water column in the chamber oscillates due to the effect of the waves, making the trapped air flow in and out the chamber through the orifice and causing the rotation of the air turbine.

Finally, PAs and OSWCs are both wave-activated devices, meaning that the devices themselves move due to the action of the waves. The devices are connected to a power take-off (PTO) system that converts 


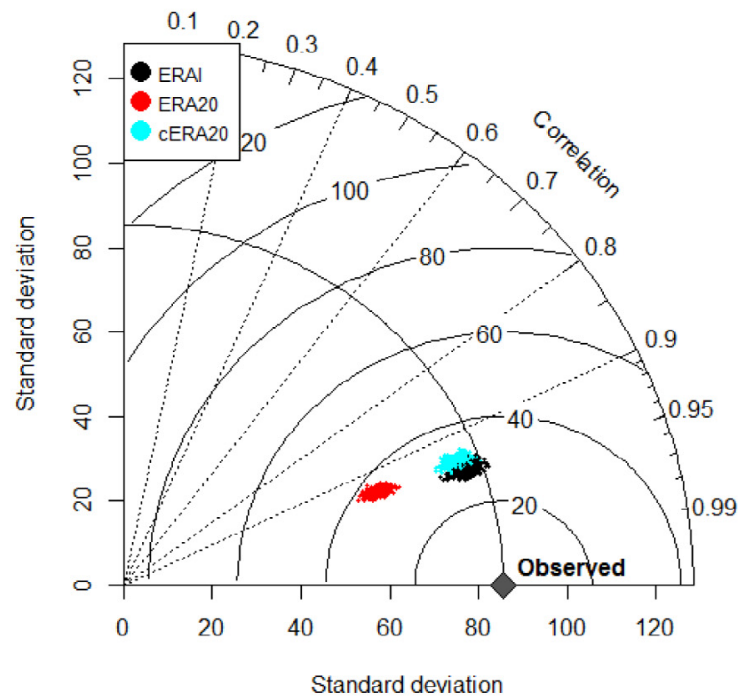

M1

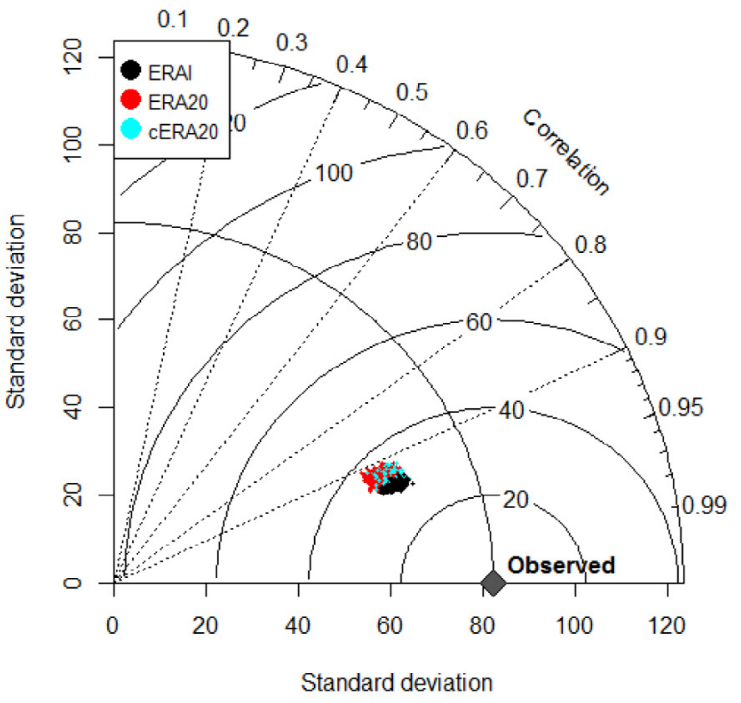

M4

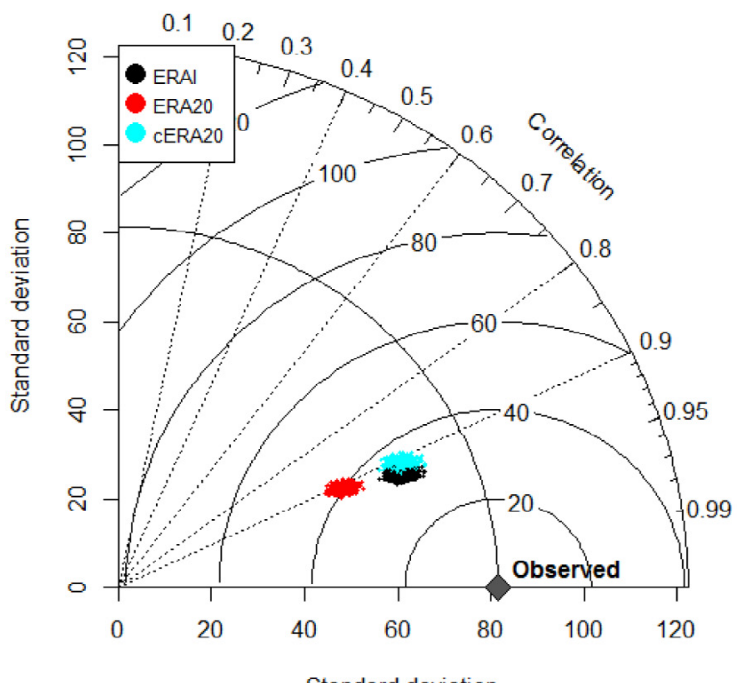

M3

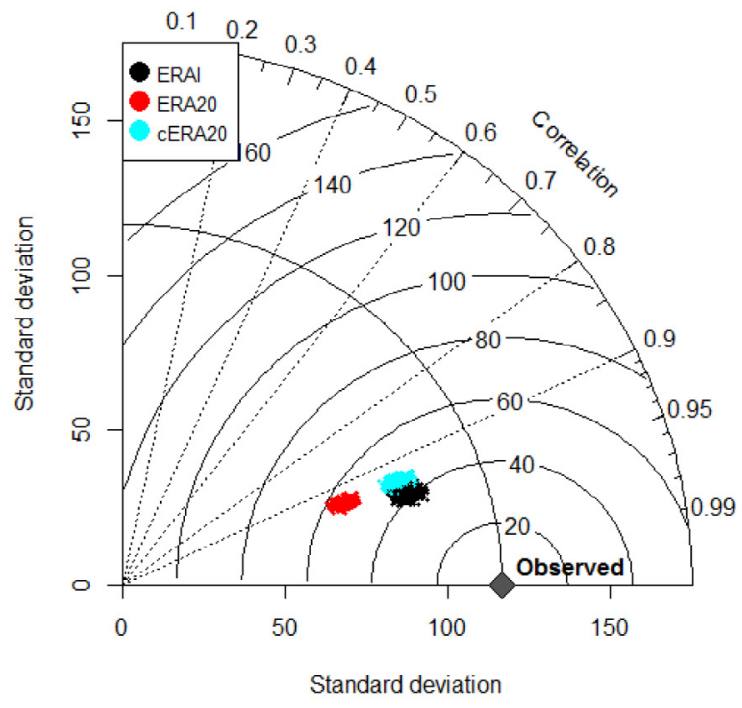

M6

Fig. 4. Taylor Diagrams of ERA20, ERAI and cERA20 in the four buoys.

the motion of the device into electricity. PAs can use different DoFs, while OSWCs harvest the energy from the waves using the pitch mode around the hinge, as illustrated in Fig. 7(b) and (c), respectively. OSWCs are predominantly designed to be installed in shallow waters near-shore, while PAs are generally deployed in deep water, far from shore.

In the previous preliminary study by the authors [29], a generic spherical heaving PA is used to analyse the impact of the historical wave trends. In order to analyse the real impact of wave energy resource variations on WECs, realistic WECs are considered. However, the impact of these variations may vary from one WEC type to another and, thus, the realistic WECs considered in the analysis should cover different possibilities to absorb energy from ocean waves. Following the three classification methods described in this section, the WECs considered in the present study should cover different working principles, sizes and deployment locations with respect to the coastline. The vast majority of real WECs suggested in the literature are PAs, OSWCs and OWCs, with only two large scale (over $1 / 3$ scale) overtopping devices deployed in the last decades [58]. In addition, the size and location of floating OWC devices are similar to PAs, which suggests that the impact of resource variations will also be similar. Therefore, including a small heave-surge PA deployed offshore in deep-water and a large fixed OSWC deployed near-shore, the characteristics of the main WECs are covered.

\subsection{Hydrodynamic model}

An estimation of the power absorption of a WEC in a given location can be analysed appropriately combining the power matrix of the device and the scatter diagram or probability density function (PDF) at the desired location.

The power matrices in the previous study of the authors [29] are obtained by using a basic frequency-domain model. In the present study, a time-domain model is implemented, including nonlinear viscous effects, constraints for displacement, velocity and PTO force, and optimising the PTO force in time-domain. Aspects like drift forces or forces induced by ocean currents and wind are neglected in the present study. The mathematical model used in the present paper is shown in Appendix A. 


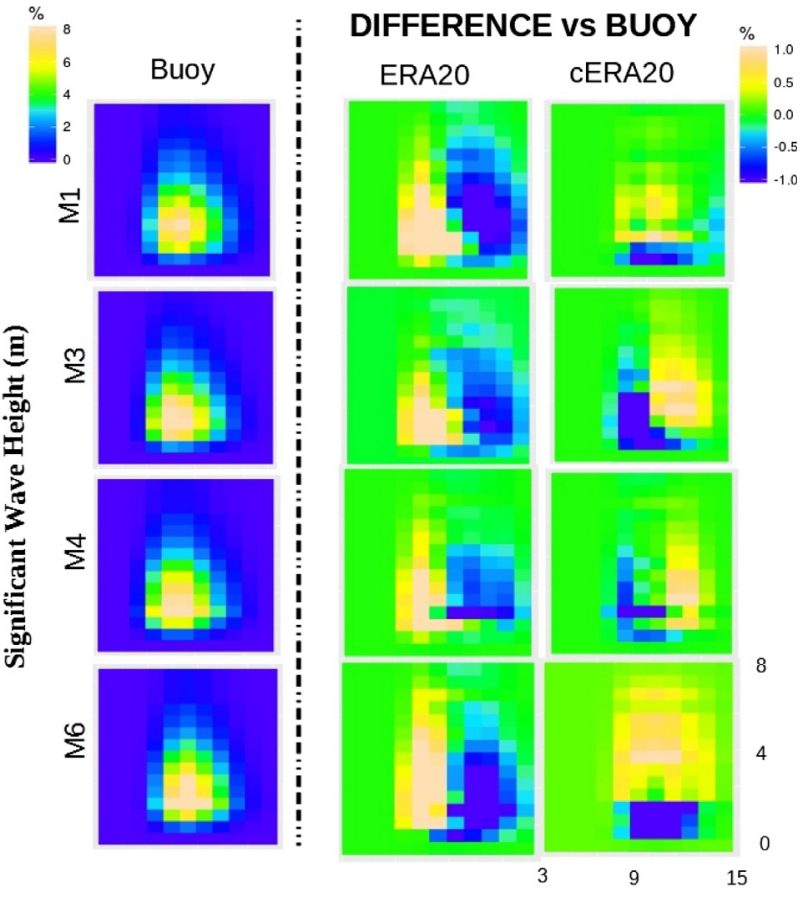

Peak Period (s)

Fig. 5. Scatter diagrams of the for locations presented in Table 1 calculated from buoy measurements, and the ERA20 and cERA20 reanalyses.

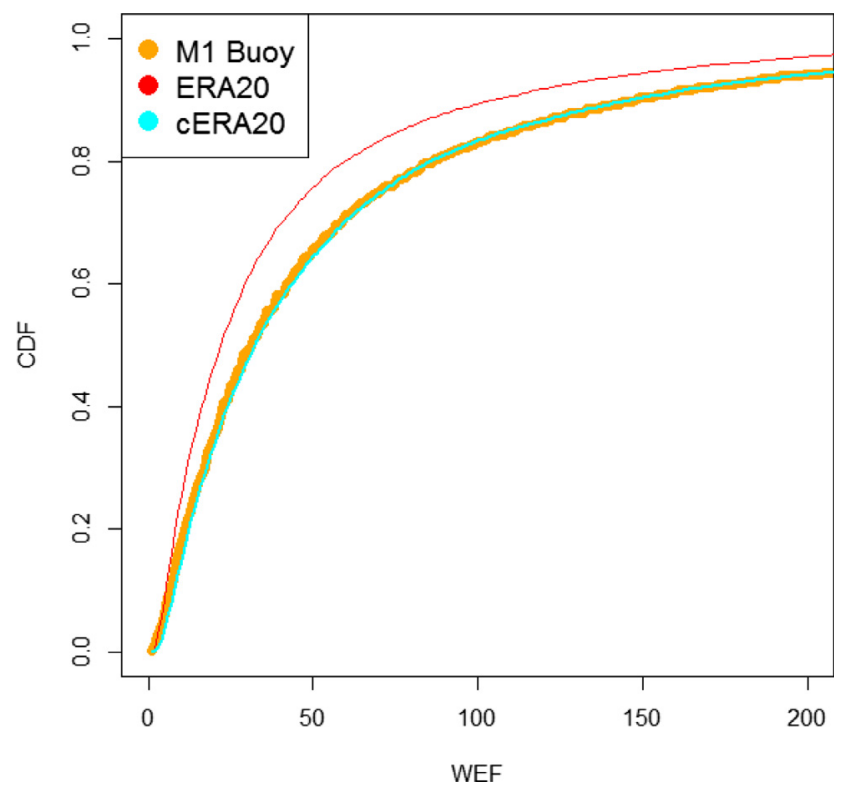

Fig. 6. Illustrating quantile-matching calibration for wave every over CDF curves at M1 buoy.

\subsection{Realistic wave energy converters}

The PA and the OSWC used in the present paper are inspired by the Corpower [59] and the Oyster [60] devices, respectively. Fig. 8 shows the two real devices and their power matrices, and Table 4 presents their geometrical characteristics.

The PTO force is implemented in the mathematical models of both devices as described in Eq. (A.4). However, in the case of the OSWC, the PTO stiffness $\left(K_{P T O}\right)$ is always positive, which is feasible in realistic PTO systems commonly used in OSWC, such as hydraulic systems. The negative $K_{P T O}$ effect, although allows for significant power absorption improvements [61], is harder to achieve in real PTO systems, because involves sucking energy from the electricity grid and through the PTO drivetrain [62]. However, Corpower claims to be an 'inherently phasecontrolled' WEC, which means that the effect of the negative $K_{P T O}$ is achieved inherently by means of a passive pneumatic machinery component called WaveSpring [59]. Therefore, negative $K_{\text {Рто coefficients }}$ are also considered when optimising the control of the PA.

Due to the use of realistic WEC geometries and more precise numerical models, results of this study show more realistic consequences to be expected by the developers as a consequence of the variations in wave energy resources.

\section{Results}

\subsection{Wave energy trends}

Datasets obtained from CERA20 can now be used to evaluate wave energy trends along the 20th century in Ireland. Although the present paper focuses on the west coast of Ireland, wave trends are first analysed for all Europe, to provide a better spatial understanding of the WEF variations before focusing on the area of interest. Fig. 9(a) illustrates the wave trends in Europe calculated with ERA20, while Fig. 9(b) shows the influence of the calibration when analysing WEF variations, showing the difference between cERA2O and ERA20. Hence, Fig. 9(b) demonstrates once again the overall underestimation of WEF variations in Europe when directly using the ERA20 reanalysis. However, it should be noted that differences between ERA20 and cERA20 are insignificant in some areas, particularly in closed protected areas, such as the Mediterranean Sea, the Black Sea, the North Sea and the Baltic Sea.

The west coast of Ireland is shown to be a hot area in Fig. 9(a), where increments of wave power of up to $1 \mathrm{~kW} / \mathrm{m}$ per decade are shown, i.e. a relative increment over the 20th century of approximately $15 \%$ considering a mean WEF of $60 \mathrm{~kW} / \mathrm{m}$. However, Fig. 9(b) shows a differences of up to $0.5 \mathrm{~kW} / \mathrm{m}$ between $c E R A 20$ and ERA20, which implies a relative positive trend of $22 \%$ over the whole century.

Apart from the need to consider the calibration, Fig. 9 highlights the interest of the target area of this paper. The west coast of Ireland shows an enormous wave energy resource and a high variability of the resource. Fig. 10(a), (b) and (c) illustrate wave trends for $H_{s}, T_{m}$ and WEF, respectively, which are positive for the whole area of interest. These positive trends become more significant towards the open Atlantic Ocean, and the wave period trend also shows large variations in the north of the island. The maximum increase of $H_{s}, T_{m}$ and WEF trends are respectively $6 \mathrm{~cm}, 7 \mathrm{cen}$ tiseconds (cs) and $1.6 \mathrm{~kW} / \mathrm{m}$ per decade, which correspond to over $0.5 \mathrm{~m}$, $0.65 \mathrm{~s}$ and $15 \mathrm{~kW} / \mathrm{m}$ along the 20th century. These trends in absolute values are significantly higher than the absolute trends shown in [29] for the Bay of Biscay, but relative values in percentages are similar for both areas. In addition, these relative values are similar to the trends observed by Young et al. off the west coast of Ireland in their study using satellite's altimetry [12].

\subsection{Impact on power absorption}

To evaluate the consequences of the wave energy resource variations on realistic wave energy converters, PDF diagrams as function of $H_{s}$ (Y axis) and $T_{p}$ (X axis) are calculated every do-decade, i.e. every two decades, over the 20th century. Fig. 11 illustrates the PDF diagrams using the calibrated data for the five do-decades, based on the data generated for the M1 buoy. The referential PDF diagram corresponds to the first do-decade and is shown at the top of Fig. 11. PDF diagrams of the following four do-decades are represented below the referential diagram as differential PDFs with respect to the referential. Hence, one can observe the progressive displacement of positive probabilities towards higher wave heights and periods and negative probabilities towards lower heights and periods, with significant leaps in the 40s and the 60 s. 


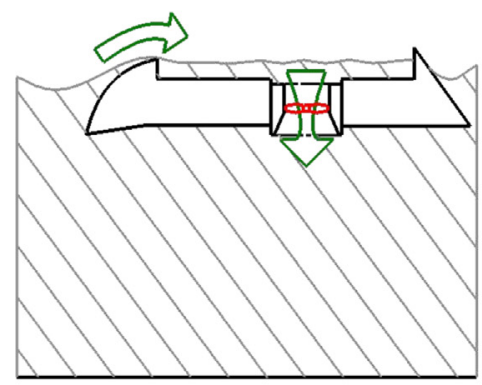

(a)

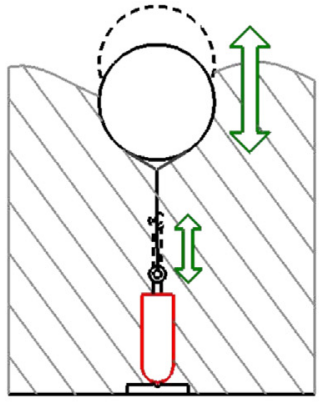

(b)

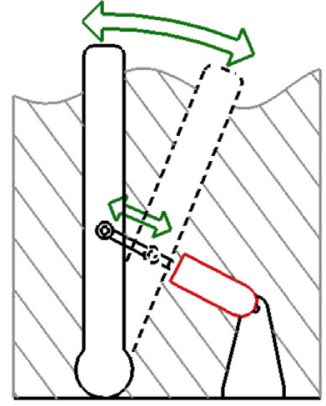

(c)

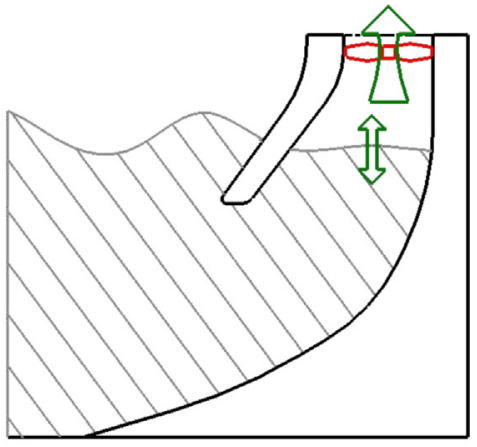

(d)

Fig. 7. Different wave energy converters based on different working principles: (a) overtopping device, (b) PA, (c) OSWC and (d) OWC.

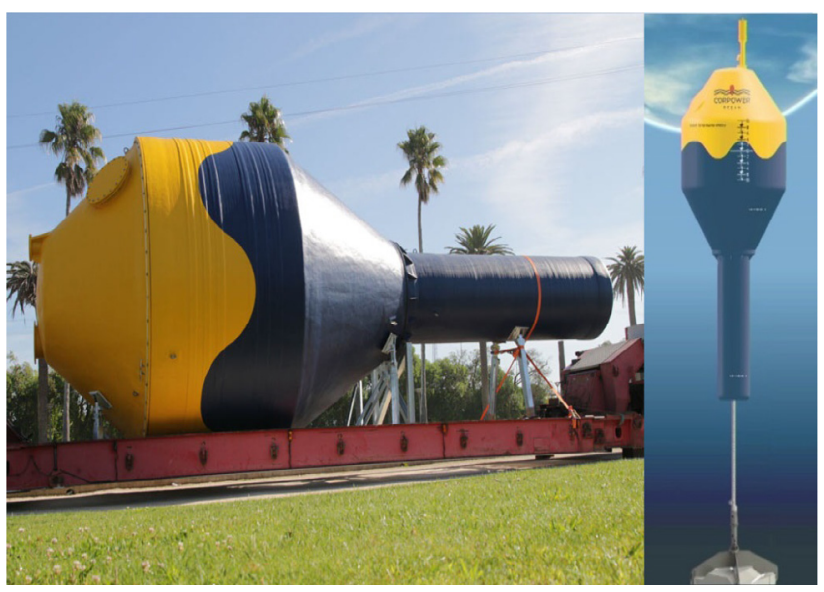

(a) Corpower device.

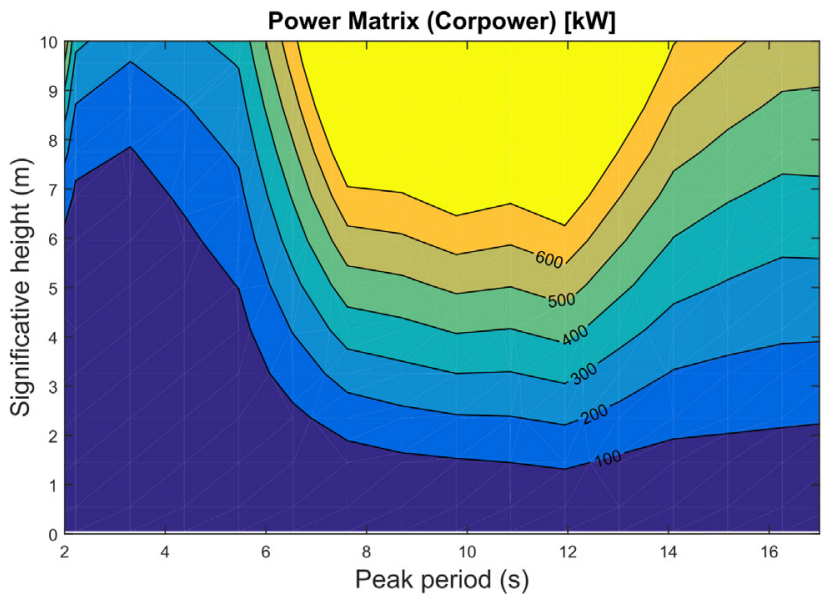

(c) Power matrix of the Corpower device

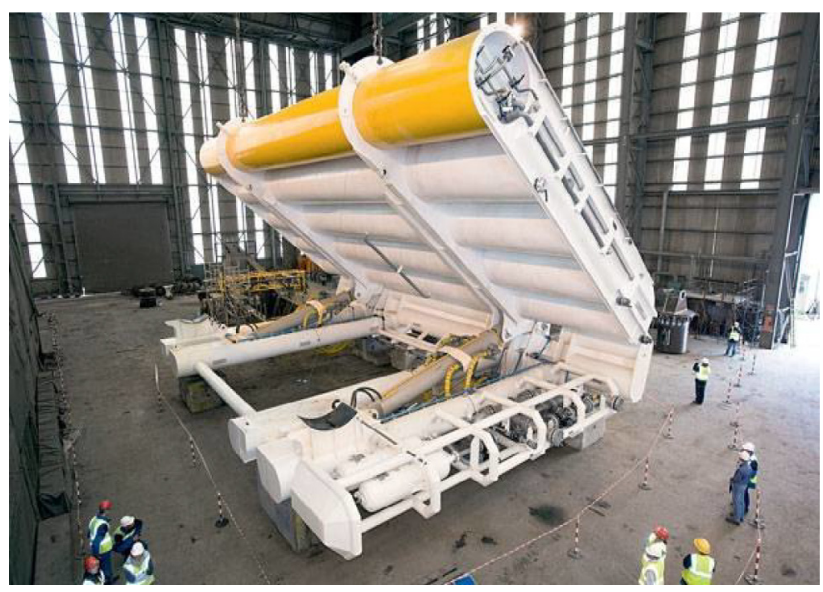

(b) Oyster device.

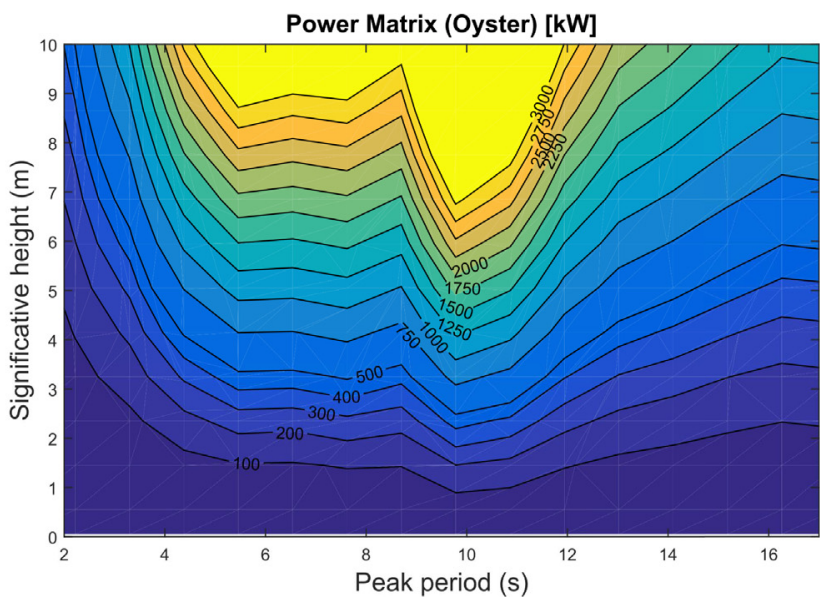

(d) Power matrix of the Oyster device.

Fig. 8. Pictures of the Corpower (a) and Oyster (b) WECs, and their power matrix in (c) and (d), respectively.

This historical displacement towards more energetic sea events is also illustrated in Fig. 12 for $H_{s}, T_{p}$, and WEF, where each bar corresponds to the cumulative increment of the mean value with respect to the referential do-decade. Although the increment in wave period appears to be moderate, the three parameters that characterise the wave resource increase progressively. The increase of mean $H_{s}$ and $T_{p}$ between 1920 and 1940 is almost imperceptible, while the mean WEF decreases in the same period. This negative increment in WEF appears because the WEF is proportional to $H_{s}^{2}$ (not $H_{s}$ ), which also includes negative increment values despite the positive trend shown by $H_{s} .{ }^{1}$ The three parameters increase considerably between 1940 and 2000, with the WEF increasing 12 and $18 \%$ in the last two do-decades, respectively. In addition, the WEF appears to increase quadratically, which suggests that the expected increase in the following do-decades will be more dramatic. Finally, it should be noted that results for the last do-decade are particularly

\footnotetext{
${ }^{1}$ Depending on the distribution, the mean of the square can be lower than the square of the mean $\left(\right.$ mean $\left(H_{s}^{2}\right)<$ mean $\left.\left(H_{S}\right)^{2}\right)$.
} 
Table 4

Main geometrical characteristics of the two real WECs: Corpower, based on [59], and Oyster, based on [63].

\begin{tabular}{cccc}
\hline Main geometrical parameters & Corpower [59] & Oyster [63] & Unit \\
\hline Water depth & 80 & 13 & $\mathrm{~m}$ \\
Buoy height & 18 & - & $\mathrm{m}$ \\
Buoy diameter & 8.4 & - & $\mathrm{m}$ \\
Buoy draft & 16.8 & - & $\mathrm{m}$ \\
Flap height & - & 13 & $\mathrm{~m}$ \\
Flap draft & - & 9 & $\mathrm{~m}$ \\
Flap thickness & - & 2 & $\mathrm{~m}$ \\
Mass & 78 & $150 \mathrm{e} 3$ & $\mathrm{~kg}$ \\
Natural period & 5.2 & 17.4 & $\mathrm{~s}$ \\
\hline
\end{tabular}

relevant, since ERAI, the reanalysis used for the calibration, assimilates wave observations since 1979 .

Thus, based on the increase of WEF, a similar increment of the absorbed energy of WECs is to be expected. Therefore, any hypothetical WEC or WEC farm to be deployed off the west coast of Ireland, assuming a lifespan of between 20 and 30 years, should definitely consider these wave trends and design the devices accordingly. However, that increment may depend on many factors, such as the absorption mode or the natural period of the WEC.

Hence, the impact of the increment in WEF and the displacement of the PDF diagrams towards more energetic sea states is investigated with the two WECs defined in Section 4.2. Combining the PDF diagrams for the five do-decades with the power matrices presented in Fig. 8(c) and (d), the historical trend of the annual mean power production (AMPP) is calculated. The Corpower device would have produced $171 \mathrm{~kW}$ in the first do-decade of the 20th century, while the Oyster device would have produced $345 \mathrm{~kW}$. Using those values as the basis, Fig. 13 illustrates the increment in percentage of the AMPP for each device. Although the AMPP of both devices increases along the century, the increment of the Corpower device is higher in the second and third do-decades, while the AMPP of the Oyster device increases faster in the last two do-decades.

These differences between the Corpower and the Oyster devices are connected to the variations of $T_{p}$. The wave resource evolves towards more energetic sea-states, as illustrated in Fig. 11, meaning that the $T_{p}$ of the sea-state with the highest ocurrence also increases along the century. Therefore, the resource approaches the natural period of the Oyster device (17.4 s), which explains the faster increment of the AMPP at the final do-decades.

ERA20

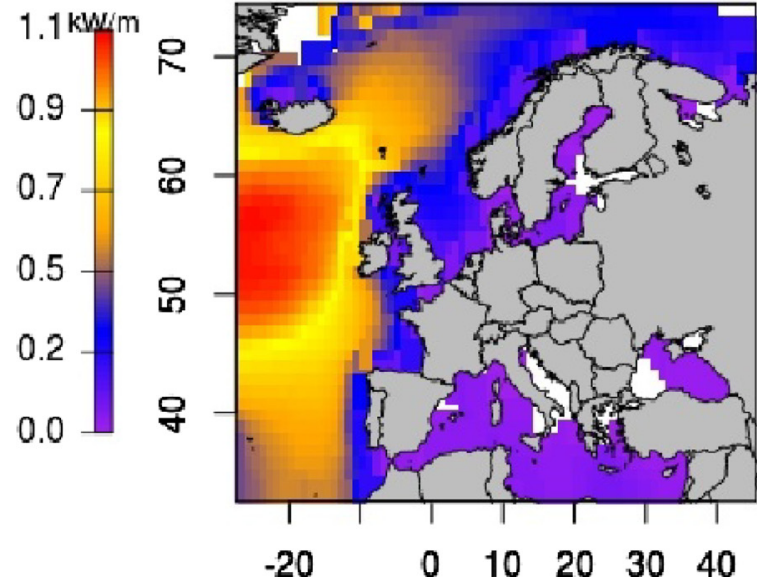

\subsection{Extreme events}

Apart from absorbing energy from ocean waves, WECs must survive the harsh conditions in the ocean, which is identified as one of the main challenges for wave energy converters. To that end, WECs usually include a second-level operation mode, known as the survivability mode, under which the aim of the WEC is to protect the different components and minimise structural damages. Hence, an operational space is usually defined for each WEC, similarly to other renewable energy technologies like wind turbines, above which the WEC switches to survivability mode and produces no electricity.

The limit between operation and survivability modes for different WECs is defined, in general, as a maximum $H_{s}\left(H_{s}^{M A X}\right)$. Diverse $H_{s}^{M A X}$ values have been suggested in the literature for different devices: a PA and an OSWC are studied in both $[64,65]$, where the limits $H_{s}^{M A X}=4 \mathrm{~m}$ and $H_{s}^{M A X}=5 \mathrm{~m}$ are suggested, respectively; a proper operational space, with limits in $T_{p}$ and $H_{s}$, is defined in [66] for the Oyster device, where $H_{s}^{M A X}=5.5 \mathrm{~m}$; and $H_{s}^{M A X}=10 \mathrm{~m}$ is used in [67] for the Corpower device. Due to the inconsistency among the different studies and the uncertainty to define a reasonable $H_{s}^{M A X}$, a number of different $H_{s}^{M A X}$ values are analysed in the present paper to evaluate the impact of resource variations on the overall performance of WECs.

Extreme events are defined in this paper as the sea-states off the operational region delimited by $H_{s}^{M A X}$. The evolution of the wave energy resource off the west coast of Ireland leads to a significant increase of the occurrence of extreme events along the 20th century, as illustrated in Fig. 14 for different $H_{s}^{M A X}$ values.

The number of hours the device operates in survival mode increases considerably, almost doubles from the beginning of the century to the end, for all the different $H_{s}^{M A X}$ values. For $H_{s}^{M A X} \geqslant 6 \mathrm{~m}$, extreme events represent less than $1 \%$ of the total operation time at the end of the 20th century, while with $H_{s}^{M A X}=4 \mathrm{~m}$ the device spends almost $10 \%$ of the time in survival mode. Depending on the operational region defined for the WEC, the increase in AMPP illustrated in Fig. 13 can be significantly reduced. In fact, the increase of WEF shown in Fig. 12 partly corresponds to extreme events in which the WEC switches into survival mode. Fig. 15(a) and (b) respectively illustrate AMPP variations with respect to the non-limited case $\left(H_{s}^{M A X}=\infty\right)$ for the Corpower and the Oyster WECs, comparing different $H_{s}^{M A X}$ values to delimit the operational regions.

The increase of extreme events along the 20th century has a significant impact on the energy absorption of WECs, as illustrated in Fig. 15. The increment of extreme events along the 20th century for the $H_{s}^{M A X}=4 \mathrm{~m}$ case (from 4 to $8 \%$, as shown in Fig. 14), results in an AMPP reduction of approximately $10 \%$. Similar figures are found for the operational region limit $H_{s}^{M A X}=5 \mathrm{~m}$, while less restrictive limits,

\section{cERA20-ERA20}

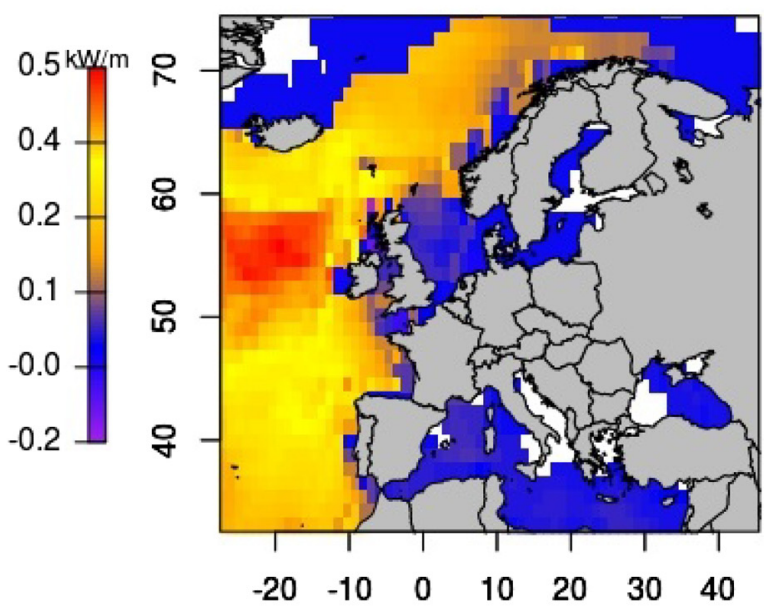

Fig. 9. Wave energy trend in Europe according to ERA2O and the difference by calibration. 


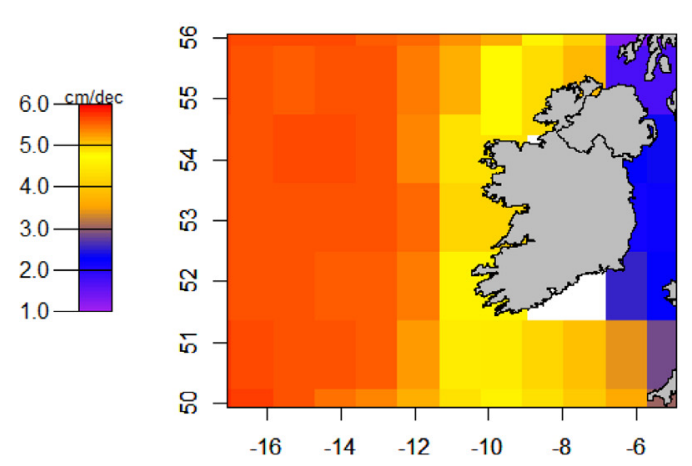

a) $H_{s}$ trend $\left(10^{-2} \mathrm{~m} / \mathrm{dec}\right)$

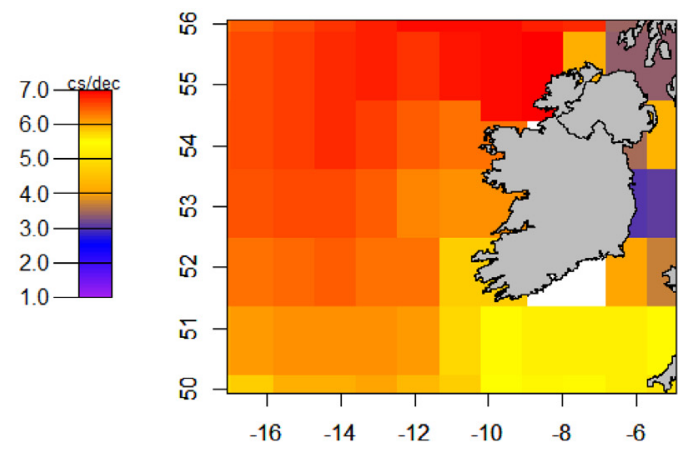

b) $T_{m}$ trend $\left(10^{-2} \mathrm{sec} / \mathrm{dec}\right)$

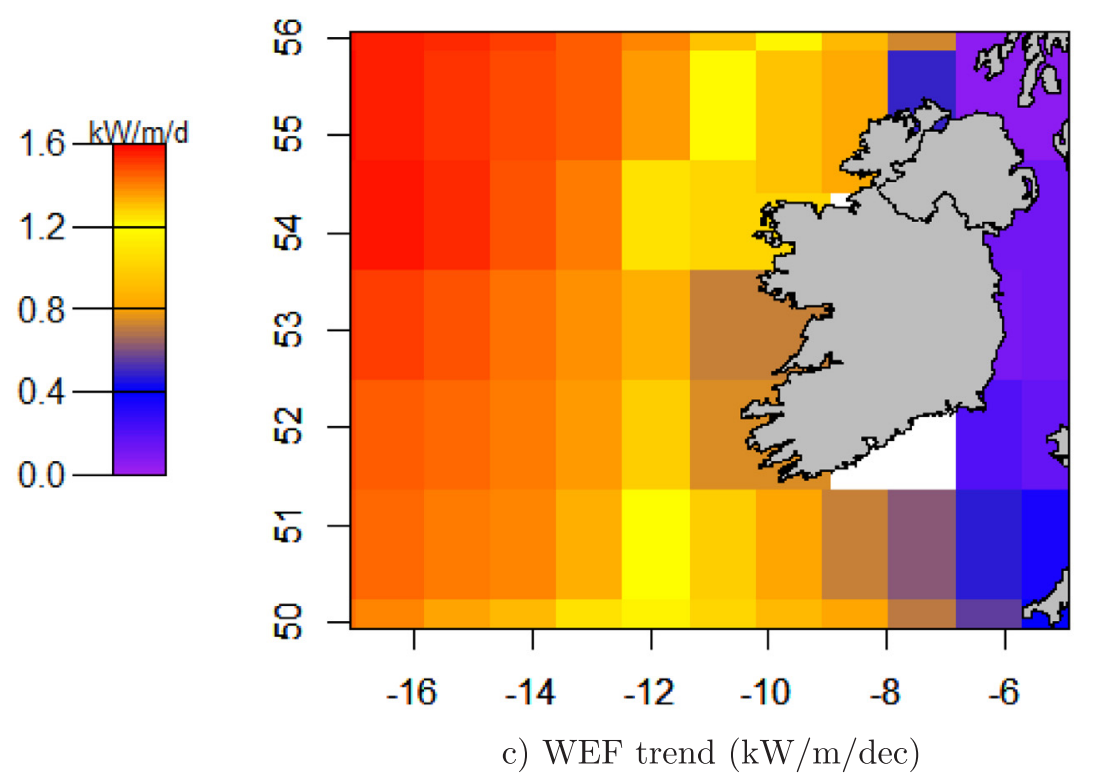

Fig. 10. Trends over Ireland.

i.e. $H_{s}^{M A X}=6 \mathrm{~m}$ and $H_{s}^{M A X}=7 \mathrm{~m}$, result in lower AMPP reductions of approximately $5 \%$ over the whole century.

\section{Discussion and future outlook}

Atmospheric reanalyses are created by the major scientific research centres using "frozen" data assimilation techniques to reprocess all the data from the available observations. These assimilation techniques produce consistent estimates for operational weather forecasts [68]. However, despite the careful preparation of historical reanalyses, some spurious trends estill exist in the assimilated data. The evolution of measuring technologies, especially after the introduction of satellite data $[69,70]$, has a significant impact on the reanalyses, due to the vast available data for assimilation [71,72]. However, this impact is lower in modern reanalyses [73]. The uncertainty of the reanalyses of the early 20th century may be a potential issue in the present paper, due to the scarcity of observations at that time [74]. The calibration via quantile-matching presented in this paper, developing and validating a new method of calibration for historical wave energy trends, is a way to minimise these uncertainties.

In any case, wave energy resource variations and, especially, their impact on realistic WEC's power absorption presented in this paper are significant enough to consider resource variations in the design of future WECs and WEC farms. Variations of the wave energy resource result in considerable increases of the AMPP, which directly affects the part of the WEC design related to power generation. On the one hand, the optimal sizing of the different components in the PTO system, such as the hydraulic motor, the electric generator or the power converters, may vary substantially, leading to unefficient power absorption if resource variations are neglected. On the other hand, electric components that allow for the integration of the generated electricity into the national electric grids, such as cables and transformers, can be poorly designed unless resource variations are considered.

In addition, the present paper shows an increase of extreme events along the 20th century. These type of trends have not been considered in previous studies and are shown to have significant consequences on WECs. This paper highlights the importance of adequately defining the operational region, which substantially affects the structural design of the absorber, anchors and mooring lines.

Therefore, neglecting resource variations and historical wave trends in the design of WECs can result in unexpected generated power reductions, due to inefficient PTO systems or excessive periods spent in survival mode, which may significantly delay the payback period of the investment. More dramatically, underestimating resource variations may lead to catastrophic consequences, such as structural damages that require financially unviable maintenance operations or the loss of a device due to a fracture in mooring lines or the anchors.

\subsection{Future works}

In future studies, the uncertainties of the reanalyses should be considered. Thus, an interesting future line of research may be a sensitivity analysis of the quantile matching technique with respect to the length of the 

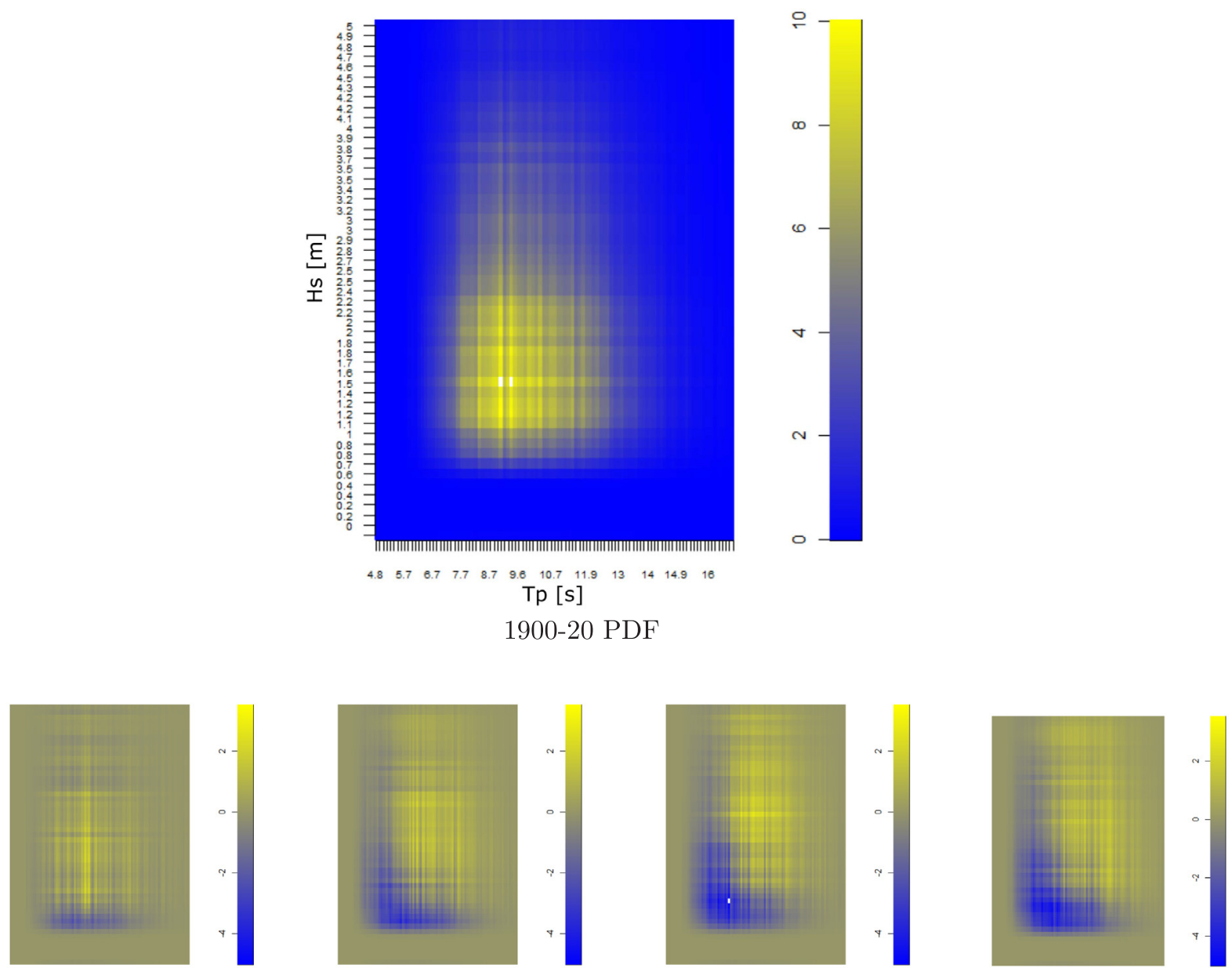

1920-40 differential PDF

1940-60 differential PDF

1960-80 differential PDF 1980-2000 differential PDF

Fig. 11. On the top, the absolute PDF of the first do-decade, and below the differential PDFs of the next four do-decades with respect to the first one.

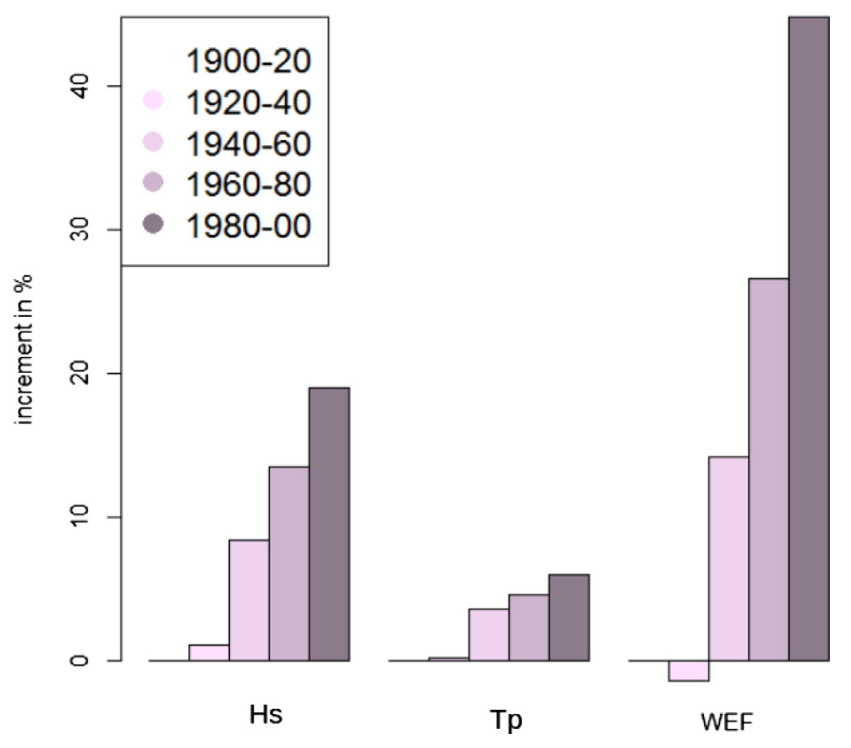

Fig. 12. Increments in percentage of each do-decade with respect to the first one for the mean values of $H_{s}, T_{p}$ and WEF.

period used to perform the matching.

Another research line to complete the present study, is incorporating mathematical models of a realistic PTO system and

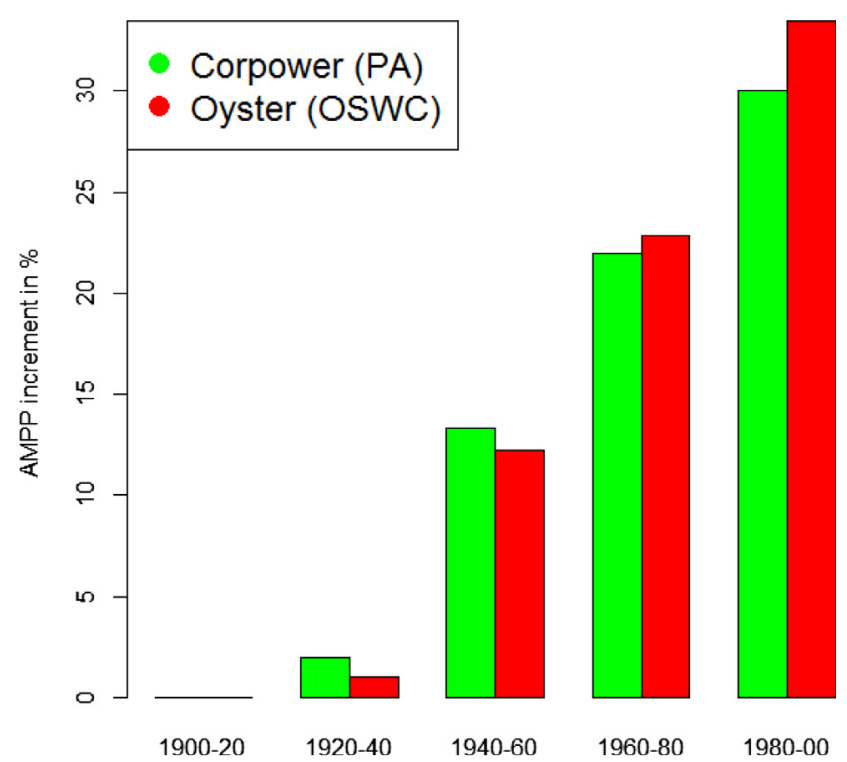

Fig. 13. Increments in percent in each do-decade with respect to the first one for the AMPP of the two WECs.

mooring lines, in order to better understand the impact of resource variations. The PTO model provides the chance to analyse the sensitivity of the components' sizing to resource variations, while including 


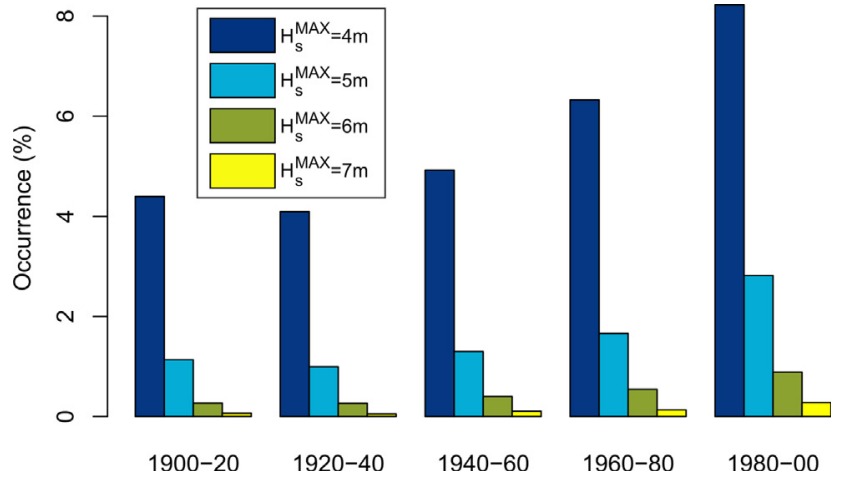

Fig. 14. Occurrence of extreme events over the 20th century for different $H_{s}^{M A X}$ values. different representations of physical processes at subgrid scales, and the different existing Representative Concentration Pathways (RPC, formerly known as socio-economic scenarios).

\section{Conclusions}

The paper presents a novel method to assess wave energy resource variations along the whole 20th century and their impact on the energy production of wave energy converters, including the influence of historical wave trends and variations of extreme events. This novel method is evaluated off the west coast of Ireland for two fundamentally different realistic wave energy converters.

Wave trends over the 20th century show the evolution of the wave energy resource towards more energetic sea-states. These variations are important even within the lifespan of a wave energy converter, esti-

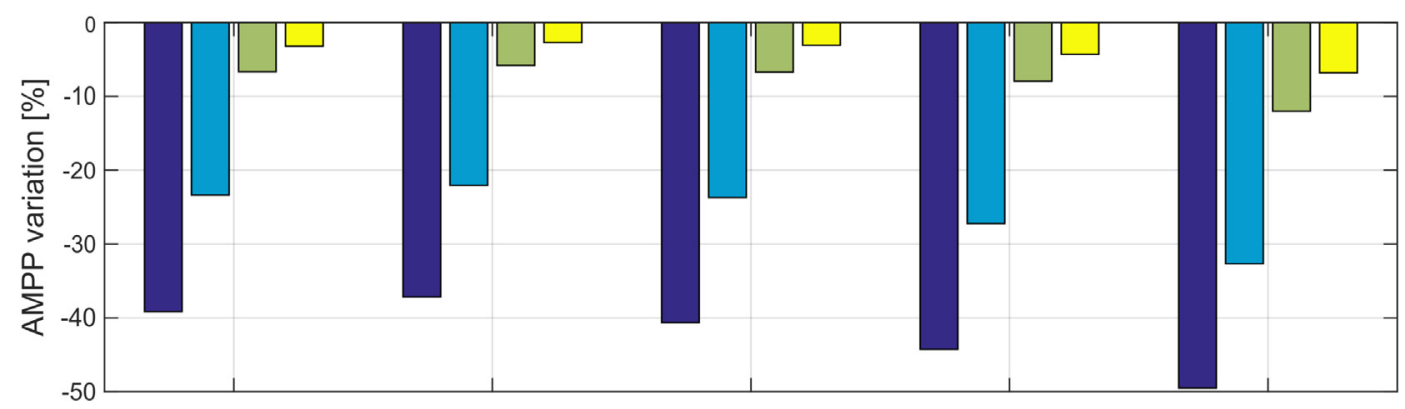

(a) Corpower

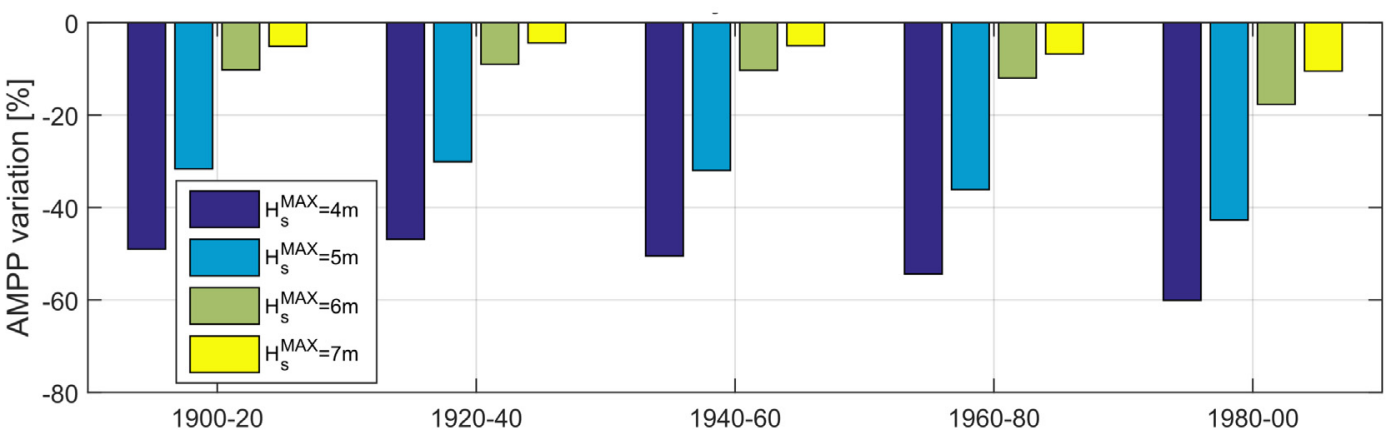

(b) Oyster

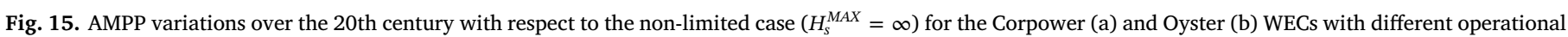
regions.

mooring lines in the model allows for a structural analysis to evaluate their resistance.

Seasonal and directional variations of the wave energy resource over the 20th century can also be considered in future studies, since knowledge on seasonal and directional variations provide essential information to adequately design WECs and select the most appropriate location to install WEC farms.

Finally, it would also be interesting to join our historical study with future projections in specific geographic areas. Future projections are usual in coastal impact assessment but can also be interesting for power assessment studies for WECs. The study of future projections requires the use of global climate models, such as the model used in the Coupled Model Intercomparison Project Phase 5 (CMIP5) experiment [75] prepared for the Fifth Assessment Report of the Intergovernmental Panel on Climate Change (IPCC). However, accurate estimations of future projections are still a major task, since wave data in climate models is usually obtained by means of numerical wave models nested in forcing fields from the global climate models [76]. Alternatively, computationally cheaper statistical downscaling models [77] can be used. In addition, the accuracy of future projections depend on two important uncertainties: biases of climate models due to the mated between 20 and 40 years, with differences in wave energy flux of up to $15 \%$ within 20 years.

The impact of resource variations in power absorption is observed in annual mean power production estimations, with increments of up to $10 \%$ within the lifespan of a wave energy converter. These differences in power production depend on the increase of wave height and period, meaning that the impact of resource variations vary depending on the working principle of the wave energy converter. Since wave trends show a considerable displacement towards higher wave periods, the impact of resource variations is larger on wave energy converters with higher natural periods.

In addition, resource variations towards more energetic sea-states mean more frequent and more powerful extreme events, doubling the occurrence of extreme events over the 20th century and, as a consequence, doubling the time devices spend in survival mode. This increase in extreme events considerably affects the power production, with reductions of up to $10 \%$.

In conclusion, the paper shows that the wave historical trends, heretofore ignored, significantly affect the performance of wave energy converters and, thus, should be considered when designing future wave energy converters, including aspects like the power take-off system, mooring lines 
or grid connection equipment.

\section{Acknowledgments}

This work has been funded by the Spanish Government, MINECO project CGL2016-76561- R (MINECO/EU ERDF), and the University of the Basque Country (projects GIU14/03 and PES17/23). The authors affiliated to the Centre for Ocean Energy Research are supported by the Science Foundation Ireland under Grant No. 13/IA/1886. Most of the calculations and plots have been carried out within the framework of $\mathrm{R}$ (R Core Team, 2016).

\section{Appendix A. Hydrodynamic model}

Essentially, the dynamical equation of the WEC is given following the Cummins equation [78] as follows:

$\left(M+\mu_{\infty}\right) \ddot{x}(t)=F_{e x}(t)-K_{H} x-\int_{0}^{t} K_{r a d}(t-\tau) \dot{x}(\tau) d t+F_{\text {visc }}(t)+F_{P T O}(t)+F_{M O O}(t)+F_{\text {EndStop }}(t)$,

where

- $M$ and $\mu_{\infty}$ are the mass and infinite added-mass matrices of the device,

- $x(t), \dot{x}(t)$ and $\ddot{x}(t)$ are, respectively, the displacement, velocity and acceleration vectors of the device for the corresponding DoFs,

- $F_{e x}(t)$ is the excitation force vector,

- $K_{H}$ the hydrostatic stiffness,

- $K_{\text {rad }}$ the radiation impulse response vector,

- $F_{\text {visc }}$ the viscous force vector,

- $F_{P T O}$ the PTO force vector,

- $F_{M O O}$ the mooring force vector (if required), and

- $F_{\text {EndStop }}$ the force that reproduced the end-stop effect of the PTO mechanism.

The wave-structure interaction is modelled via the linear potential theory, which assumes an inviscid and incompressible fluid, irrotational flow and small motion amplitudes of the WEC. Frequency-domain (FD) hydrodynamic coefficients are obtained with the boundary element method (BEM) code NEMOH [79]. Hence, using the excitation force FD coefficient $\left(F_{e x}(f)\right)$ and a spectral density function $(S(f))$ based on the JONSWAP spectrum [80], the wave excitation force signal can be obtained for each sea-state [81] as follows:

$F e(t)=\sum_{k=1} A_{k} F_{e x}\left(f_{k}\right) \cos \left(2 \pi f_{k} t+\phi_{k}\right)$

where $A_{k}=\sqrt{2 S\left(f_{k}\right) \Delta f}, f_{k}$ is the frequency, $\Delta f$ the frequency step and $\phi_{k}$ a set of random phases.

\section{A.1. Viscous force}

Fully linear models are shown to overestimate the motions of the devices, and, as a consequence, the power absorption [82]. Viscous effects are identified to be important for both PAs and OSWCs in [83] and are modelled, in the vast majority of the cases, via the Morison's equation [84], using a quadratic damping term known as the drag coefficient $\left(C_{D}\right)$ :

$F_{\text {visc }}(t)=\frac{1}{2} \rho C_{D} A_{D}\left(\dot{x}-V_{0}\right)\left|\dot{x}-V_{0}\right|$

where $\rho$ is the water density, $A_{D}$ the characteristic area of the WEC and $V_{0}$ the velocity of the undisturbed flow.

Apart from viscous effects, no other nonlinear effect is included in the models. Similar models have widely been used in the literature for power production assessment [63]. In any case, the goal of the present paper is to evaluate power production variations as a consequence of resource variations. Therefore, the authors believe that the linear model with viscous effects is appropriate for such an investigation.

\section{A.2. Power take-off and mooring forces}

Several PTO systems have been suggested in the literature [85], such as hydraulic systems [86], air turbines [87] or mechanical gear-boxes [88] coupled to a rotary electrical generator, and direct drive systems [89]. In the present paper, the PTO system is modelled via a linear model:

$F_{P T O}(t)=-K_{\text {РTO }} x-B_{\text {PTO }} \dot{x}$

where $B_{\text {РтО }}$ is the linear PTO damping. The damping term is the dissipative term that absorbs energy from ocean waves, while the stiffness is required to increase the absorbed power. This linear PTO model is also known as reactive control.

The damping and stiffness coefficients have been optimised for each sea-state to maximize the energy absorption. The optimisation is carried out via the exhaustive search algorithm, ensuring that the optimal value is always the global maximum.

With respect to the moorings, only the PA needs to include the effect of the moorings in the mathematical model, since the OSWC is directly mounted on the seabed. Mooring systems in the PA are modelled by using simple linear springs.

\section{A.3. Constraints}

Wave energy converters are, in general, designed to operate in a specific range of conditions, and, as a consequence, the PTO system is designed to operate within these conditions. Therefore, the PTO system may have limitation when extracting energy from ocean waves. The main PTO limitations include maximum displacement (end stop), maximum velocity and maximum applicable force.

These three constraints are included in the mathematical models of the present study, but only the displacement limitation requires a new force $\left(F_{\text {EndStop }}\right)$ to implement such constraint. This force can be modelled as a spring and/or damping that activates as soon as the motion amplitude reaches 
a threshold value close to the end stop, applying a force opposite to the motion. A simple linear end stop damping $\left(B_{\text {EndStop }}\right)$ has been implemented in this study.

\section{References}

[1] REN21. Renewables 2017 global status report. Tech. rep. REN21 Secretariat, Paris; 2017. http://dx.doi.org/10.1016/j.rser.2016.09.082. < http://www.ren21.net/ wp-content/uploads/2017/06/17-8399_GSR_2017_Full_Report_0621_Opt.pdf >

[2] Mork G, Barstow S, Kabuth A, Pontes MT. Assessing the global wave energy potential. In: 29th international conference on ocean, offshore and arctic engineering; 2010. p. 447-54. http://dx.doi.org/10.1115/OMAE2010-20473.

[3] Edenhofer O, Pichs-Madruga R, Sokona Y, Seyboth K, Eickemeier P, Matschoss P, et al. IPCC special report on renewable energy sources and climate change mitigation. Intergovernmental panel on climate change; 2011. http://dx.doi.org/10. 5860/CHOICE.49-6309. < http://srren.ipcc-wg3.de/report > .

[4] Falcão AdO. Wave energy utilization: a review of the technologies. Renew Sustain Energy Rev 2010;14(3):899-918.

[5] Nielsen K, Pontes T. Generic and site related wave data. Final technical report T021.1. OES-IEA; 2010.

[6] World Metheorological Organization. Calculation of monthly and annual 30-year Standard Normals. WCDP-No. 10. WMO-TD/No. 341. Tech. rep.; 1989.

[7] The role of climatological normals in a changing climate. wcdmp-61, wmo-td/1377, Tech. rep. World Metheorological Organization; 2007.

[8] Ruggiero P, Komar PD, Allan JC. Increasing wave heights and extreme value projections: the wave climate of the US Pacific Northwest. Coast Eng 2010;57(5):539-52.

[9] Gulev SK, Grigorieva V. Last century changes in ocean wind wave height from global visual wave data. Geophys Res Lett 2004;31(24).

[10] Gulev S, Grigorieva V. Variability of the winter wind waves and swell in the north atlantic and north pacific as revealed by the voluntary observing ship data. J Clim 2006;19(21):5667-85.

[11] Woolf DK, Challenor P, Cotton P. Variability and predictability of the north atlantic wave climate. J Geophys Res: Oceans 2002;107(C10).

[12] Young I, Zieger S, Babanin AV. Global trends in wind speed and wave height. Science 2011;332(6028):451-5.

[13] Sterl A, Komen G, Cotton P. Fifteen years of global wave hindcasts using winds from the European centre for medium-range weather forecasts reanalysis: validating the reanalyzed winds and assessing the wave climate. J Geophys Res: Oceans 1998;103(C3):5477-92.

[14] Cox AT, Swail VR. A global wave hindcast over the period 1958-1997: validation and climate assessment. J Geophys Res 2001;106(C2):2313-29.

[15] Wang XL, Zwiers FW, Swail VR. North atlantic ocean wave climate change scenarios for the twenty-first century. J Clim 2004;17(12):2368-83.

[16] Wang XL, Swail VR. Climate change signal and uncertainty in projections of ocean wave heights. Clim Dyn 2006;26(2-3):109-26.

[17] Bertin X, Prouteau E, Letetrel C. A significant increase in wave height in the north atlantic ocean over the 20th century. Global Planet Change 2013;106:77-83. http://dx.doi.org/10.1016/j.gloplacha.2013.03.009.

[18] Zheng C, Shao L, Shi W, Su Q, Lin G, Li X, et al. An assessment of global ocean wave energy resources over the last 45 a. Acta Oceanol Sin 2014;33(1):92-101. http://dx. doi.org/10.1007/s13131-014-0418-5.

[19] Reguero B, Losada I, Méndez F. A global wave power resource and its seasonal, interannual and long-term variability. Appl Energy 2015;148:366-80. http://dx. doi.org/10.1016/j.apenergy.2015.03.114.

[20] Zheng CW, Wang Q, Li CY. An overview of medium- to long-term predictions of global wave energy resources. Renew Sustain Energy Rev 2017;79:1492-502. http://dx.doi.org/10.1016/j.rser.2017.05.109.

[21] Bouws E, Jannink D, Komen G. The increasing wave height in the north atlantic ocean. Bull Am Meteorol Soc 1996;77(10):2275-7.

[22] Gulev SK, Cotton D, Sterl A. Intercomparison of the north atlantic wave climatology from voluntary observing ships, satellite data and modelling. Phys Chem Earth 1998;23(5):587-92.

[23] Patra A, Bhaskaran PK. Temporal variability in wind-wave climate and its validation with ESSO-NIOT wave atlas for the head Bay of Bengal. Clim Dyn 2016:1-18.

[24] Camus P, Losada IJ, Izaguirre C, Espejo A, Menéndez M, Pérez J. Statistical wave climate projections for coastal impact assessments. Earth's Future 2017;5:918-33. http://dx.doi.org/10.1002/2017EF000609.

[25] Caires S, Sterl A, Gommenginger C. Global ocean mean wave period data: validation and description. J Geophys Res: Oceans 2005;110(C02003).

[26] Mackay E, Retzler C, Challenor P, Gommenginger C. A parametric model for ocean wave period from Ku band altimeter data. J Geophys Res: Oceans 2008;113(C3).

[27] Gommenginger C, Cotton D, Srokosz M, Challenor P. Ocean wave period from satellite altimeters: validation for Envisat RA2. In: Proc. Envisat ERS Symp.; 2005.

[28] Gommenginger C, Srokosz M, Challenor P, Cotton P. Measuring ocean wave period with satellite altimeters: a simple empirical model. Geophys Res Lett 2003;30(22).

[29] Ulazia A, Penalba M, Ibarra-Berastegui G, Ringwood J, Saénz J. Wave energy trends over the bay of biscay and the consequences for wave energy converters. Energy 2017;141. http://dx.doi.org/10.1016/j.energy.2017.09.099.

[30] Morim J, Cartwright N, Etemad-Shahidi A, Strauss D, Hemer M. Wave energy resource assessment along the southeast coast of australia on the basis of a 31-year hindcast. Appl Energy 2016;184:276-97. http://dx.doi.org/10.1016/j.apenergy. 2016.09.064<http://www.sciencedirect.com/science/article/pii/ S0306261916313666>.
[31] Besio G, Mentaschi L, Mazzino A. Wave energy resource assessment in the mediterranean sea on the basis of a 35-year hindcast. Energy 2016;94:50-63. http://dx doi.org/10.1016/j.energy.2015.10.044<http://www.sciencedirect.com/science/ article/pii/S0360544215014127>

[32] Poli P, Hersbach H, Dee DP, Berrisford P, Simmons AJ, Vitart F, et al. ERA-20C: an atmospheric reanalysis of the twentieth century. J Clim 2016;29(11):4083-97.

[33] Worley SJ, Woodruff SD, Reynolds RW, Lubker SJ, Lott N. ICOADS release 2.1 data and products. Int J Climatol 2005;25(7):823-42.

[34] Dada OA, Li G, Qiao L, Ma Y, Ding D, Xu J, et al. Response of waves and coastline evolution to climate variability off the niger delta coast during the past 110 years. J Mar Syst 2016;160:64-80. http://dx.doi.org/10.1016/j.jmarsys.2016.04.005.

[35] Kumar P, Min S-K, Weller E, Lee H, Wang XL. Influence of climate variability on extreme ocean surface wave heights assessed from ERA-interim and ERA-20C. J Clim 2016;29(11):4031-46. http://dx.doi.org/10.1175/JCLI-D-15-0580.1.

[36] Berrisford P, Dee D, Fielding K, Fuentes M, Kallberg P, Kobayashi S, et al. The erainterim archive. ERA Rep Ser 2009(1):1-16.

[37] Komen GJ, Cavaleri L, Donelan M, Hasselmann K, Hasselmann S, Janssen P. Dynamics and modelling of ocean waves. Cambridge University Press; 1996.

[38] Janssen P, Bidlot J-R, Abdalla S, Hersbach H. Progress in ocean wave forecasting at ECMWF. ECMWF Technical Memory 27.

[39] IMI, Irish marine institute. < https://www.marine.ie/Home/home >

[40] Cahill B, Lewis T. Wave period ratios and the calculation of wave power. In: 2nd marine energy technology symposium METS2014, Seattle, Wash; 2014.

[41] Penalba M, Touzón I, Lopez-Mendia J, Nava V. A numerical study on the hydrodynamic impact of device slenderness and array size in wave energy farms in realistic wave climates. Ocean Eng 2017;142:224-32. http://dx.doi.org/10.1016/j. oceaneng.2017.06.047< http://linkinghub.elsevier.com/retrieve/pii/ S0029801817303517>

[42] Block P, Souza Filho F, Sun L, Kwon H-H. A streamflow forecasting framework using multiple climate and hydrological models. J Am Water Resour Assoc 2009;45(4):828-43. http://dx.doi.org/10.1111/j.1752-1688.2009.00327.x.

[43] Boé J, Terray L, Habets F, Martin E. Statistical and dynamical downscaling of the seine basin climate for hydro-meteorological studies. Int J Climatol 2007;27(12):1643-55. http://dx.doi.org/10.1002/joc.1602.

[44] Sun F, Roderick ML, Lim WH, Farquhar GD. Hydroclimatic projections for the Murray-Darling basin based on an ensemble derived from intergovernmental panel on climate change AR4 climate models. Water Resour Res 2011;47(12):n/ahttp://dx.doi.org/10.1029/2010WR009829.

[45] Piani C, Haerter JO, Coppola E. Statistical bias correction for daily precipitation in regional climate models over Europe. Theoret Appl Climatol 2010;99(1):187-92. http://dx.doi.org/10.1007/s00704-009-0134-9.

[46] Rojas R, Feyen L, Dosio A, Bavera D. Improving pan-European hydrological simulation of extreme events through statistical bias correction of RCM-driven climate simulations. Hydrol Earth Syst Sci 2011;15(8):2599-620. http://dx.doi.org/10. 5194/hess-15-2599-2011.

[47] Panofsky HA, Brier GW, Best WH. Some application of statistics to meteorology. Tech. rep. Earth and Mineral Sciences Continuing Education, College of Earth and Mineral Sciences, Pennsylvania State University; 1958

[48] Bett PE, Thornton HE, Clark RT. Using the twentieth century reanalysis to assess climate variability for the european wind industry. Theoret Appl Climatol 2015:1-20. http://dx.doi.org/10.1007/s00704-015-1591-y.

[49] Jeon S, Paciorek CJ, Wehner MF. Quantile-based bias correction and uncertainty quantification of extreme event attribution statements. Weather Clim Extremes 2016;12:24-32. http://dx.doi.org/10.1016/j.wace.2016.02.001<http://www. sciencedirect.com/science/article/pii/S2212094715300220>

[50] Teutschbein C, Seibert J. Bias correction of regional climate model simulations for hydrological climate-change impact studies: review and evaluation of different methods. J Hydrol 2012;456:12-29.

[51] Watanabe S, Kanae S, Seto S, Yeh PJ-F, Hirabayashi Y, Oki T. Intercomparison of bias-correction methods for monthly temperature and precipitation simulated by multiple climate models. J Geophys Res: Atmos 2012;117(D23).

[52] Lafon T, Dadson S, Buys G, Prudhomme C. Bias correction of daily precipitation simulated by a regional climate model: a comparison of methods. Int J Climatol 2013;33(6):1367-81.

[53] Ngai ST, Tangang F, Juneng L. Bias correction of global and regional simulated daily precipitation and surface mean temperature over Southeast Asia using quantile mapping method. Global Planet Change 2017;149:79-90. http://dx.doi. org/10.1016/j.gloplacha.2016.12.009<http://www.sciencedirect.com/science/ article/pii/S0921818116301266>

[54] Nolan G, Ringwood J, Holmes B. Short term wave energy variability off the west coast of Ireland. In: Proceedings of the 7th European wave and tidal energy conference; 2007. p. 1-10.

[55] Ringwood JV, Brandle G. A new world map for wave power with a focus on variability. In: Proceedings of the 11th European wave and tidal energy conference. European wave and tidal energy conference 2015; 2015.

[56] Drew B, Plummer AR, Sahinkaya MN. A review of wave energy converter technology. Proc Inst Mech Eng. Part A: J Power Energy 2009:223.

[57] López I, Andreu J, Ceballos S, de Alegría IM, Kortabarria I. Review of wave energy technologies and the necessary power-equipment. Renew Sustain Energy Rev 2013;27:413-34. 
[58] Babarit A. Ocean wave energy conversion. 1st ed. London, UK: Elsevier Ltd; 2016.

[59] Todalshaug JH, Asgeirsson GS, Hjálmarsson E, Maillet J, Möller P, Pires P, et al. Tank testing of an inherently phase-controlled wave energy converter. Int J Mar Energy 2016;15:68-84.

[60] Folley M, Whittaker T, Van't Hoff J. The design of small seabed-mounted bottomhinged wave energy converters. In: Proceedings of the 7th European wave and tidal energy conference, Porto, Portugal, vol. 455; 2007.

[61] Ringwood JV, Bacelli G, Fusco F. Energy-maximizing control of wave-energy converters: the development of control system technology to optimize their operation. IEEE Control Syst 2014;34(5):30-55.

[62] Polinder H, Mueller MA, Scuotto M, Goden de Sousa Prado M. Linear generator systems for wave energy conversion. In: Proceedings of the 7th European wave and tidal energy conference (EWTEC), Porto, Lisbon; 2007. p. 1-8.

[63] Babarit A, Hals J, Muliawan M, Kurniawan A, Moan T, Krokstad J. Numerical benchmarking study of a selection of wave energy converters. Renew Energy 2012:41:44-63.

[64] Mérigaud A, Ringwood JV. Power production assessment for wave energy converters: Overcoming the perils of the power matrix. Proc Inst Mech Eng Part A: J Power Energy 2018;232(1):50-70.

[65] Hiles CE, Beatty SJ, de Andres A. Wave energy converter annual energy production uncertainty using simulations. J Mar Sci Eng 2016;4(3):53.

[66] O'Boyle L, Doherty K, van't Hoff J, Skelton J. The value of full scale prototype datatesting oyster 800 at EMEC, Orkney. In: Proceedings of the 11th European wave and tidal energy conference (EWTEC), Nantes, France; 2015. p. 6-11.

[67] De Andres A, Maillet J, Hals Todalshaug J, Möller P, Bould D, Jeffrey H. Technoeconomic related metrics for a wave energy converters feasibility assessment. Sustainability 2016;8(11):1109.

[68] Kalnay E, Kanamitsu M, Kistler R, Collins W, Deaven D, Gandin L, et al. The NCEP/ NCAR 40-year Reanalysis Project 77; 1996. p. 437-71.

[69] Dee DP, Uppala SM, Simmons AJ, Berrisford P, Poli P, Kobayashi S, et al. The ERAInterim reanalysis: configuration and performance of the data assimilation system. Quart J Roy Meteorol Soc 2011;137(656):553-97. http://dx.doi.org/10.1002/qj. 828 .

[70] Sturaro G. A closer look at the climatological discontinuities present in the NCEP/ NCAR reanalysis temperature due to the introduction of satellite data. Clim Dyn 2003;21(3-4):309-16.

[71] Reichler T, Kim J. Uncertainties in the climate mean state of global observations, reanalyses, and the GFDL climate model. J Geophys Res: Atmos 2008;113(D5). http://dx.doi.org/10.1029/2007JD009278.

[72] Sterl A. On the (in)homogeneity of reanalysis products. J Clim 2004;17(19):3866-73.

[73] Simmons AJ, Poli P, Dee DP, Berrisford P, Hersbach H, Kobayashi S, et al. Estimating low-frequency variability and trends in atmospheric temperature using ERA-Interim. Quart J Roy Met Soc 2014;140:329-53. http://dx.doi.org/10.1002/ qj. 2317.

[74] Krueger O, Schenk F, Feser F, Weisse R. Inconsistencies between long-term trends in storminess derived from the $20 \mathrm{CR}$ reanalysis and observations. J Clim 2013;26(3):868-74. http://dx.doi.org/10.1175/JCLI-D-12-00309.1.

[75] Taylor KE, Stouffer RJ, Meehl GA. An overview of CMIP5 and the experiment design. Bull Am Meteorol Soc 2012;93(4):485-98.

[76] Dobrynin M, Murawsky J, Yang S. Evolution of the global wind wave climate in CMIP5 experiments. Geophys Res Lett 2012;39. http://dx.doi.org/10.1029/ 2012 GL052843.

[77] Wang XL, Feng Y, Swail VR. Changes in global ocean wave heights as projected using multimodel CMIP5 simulations. Geophys Res Lett 2014;41:1026-34. http:// dx.doi.org/10.1002/2013GL058650.

[78] Cummins W. The impulse response function and ship motion. Schiffstechnik 1962(9):101-9.

[79] Penalba M, Kelly T, Ringwood JV. Using NEMOH for modelling wave energy converters: a comparative study with WAMIT. In: Proceedings of the 12th European wave and tidal energy conference, Cork; 2017.

[80] Hasselmann K, Barnett T, Bouws E, Carlson H, Cartwright D, Enke K, et al. Measurements of wind-wave growth and swell decay during the joint north sea wave project (JONSWAP). Tech. rep. Hamburg: Deutsches Hydrographisches Institut; 1973.

[81] Mérigaud A, Ringwood JV. Free-surface time-series generation for wave energy applications. IEEE J Oceanic Eng 2018(99).

[82] Penalba M, Mérigaud A, Gilloteaux J-C, Ringwood JV. Influence of nonlinear Froude-Krylov forces on the performance of two wave energy points absorbers. J Ocean Eng Mar Energy 2017;3(3):209-20. http://dx.doi.org/10.1007/s40722-017. 0082-x.

[83] Penalba M, Giorgi G, Ringwood JV. Mathematical modelling of wave energy converters: a review of nonlinear approaches. Renew Sustain Energy Rev 2017;78:1188-207. http://dx.doi.org/10.1016/j.rser.2016.11.137< http://www. sciencedirect.com/science/article/pii/S1364032116308784 > .

[84] Morison J, Johnson J, Schaaf S, et al. The force exerted by surface waves on piles. J Petrol Technol 1950;2(05):149-54.

[85] Penalba M, Ringwood JV. A review of wave-to-wire models for wave energy converters. Energies 2016;9(7):506. http://dx.doi.org/10.3390/en9070506 < http:// www.mdpi.com/1996-1073/9/7/506>.

[86] Hansen RH, Kramer MM, Vidal E. Discrete displacement hydraulic power take-off system for the wavestar wave energy converter. Energies 2013;6(8):4001-44.

[87] Amundarain M, Alberdi M, Garrido AJ, Garrido I. Modeling and simulation of wave energy generation plants: output power control. IEEE Trans Industr Electron 2011;58(1):105-17. http://dx.doi.org/10.1109/TIE.2010.2047827.

[88] Sjolte J. Marine renewable energy conversion: grid and off-grid modeling, design and operation [Ph.D. thesis]. Norges teknisk-naturvitenskapelige universitet (NTNU), Fakultet for informasjonsteknologi, matematikk og elektroteknikk, Institutt for elkraftteknikk; 2014.

[89] Wu F, Zhang X-P, Ju P, Sterling MJ. Modeling and control of AWS-based wave energy conversion system integrated into power grid. IEEE Trans Power Syst 2008;23(3):1196-204. http://dx.doi.org/10.1109/TPWRS.2008.922530. 